\title{
Experimental Study of an Axisymmetric Dual Throat Fluidic Thrust Vectoring Nozzle for Supersonic Aircraft Application
}

\author{
Jeffrey D. Flamm*, Karen A. Deere ${ }^{\dagger}$, Mary L. Mason ${ }^{\ddagger}$, Bobby L. Berrier§, and Stuart K. Johnson ${ }^{* *}$ \\ NASA Langley Research Center, Hampton, Virginia, 23681-0001
}

\begin{abstract}
An axisymmetric version of the Dual Throat Nozzle concept with a variable expansion ratio has been studied to determine the impacts on thrust vectoring and nozzle performance. The nozzle design, applicable to a supersonic aircraft, was guided using the unsteady Reynolds-averaged Navier-Stokes computational fluid dynamics code, PAB3D. The axisymmetric Dual Throat Nozzle concept was tested statically in the Jet Exit Test Facility at the NASA Langley Research Center. The nozzle geometric design variables included circumferential span of injection, cavity length, cavity convergence angle, and nozzle expansion ratio for conditions corresponding to take-off and landing, mid climb and cruise. Internal nozzle performance and thrust vectoring performance was determined for nozzle pressure ratios up to 10 with secondary injection rates up to 10 percent of the primary flow rate. The 60 degree span of injection generally performed better than the 90 degree span of injection using an equivalent injection area and number of holes, in agreement with computational results. For injection rates less than 7 percent, thrust vector angle for the 60 degree span of injection was 1.5 to 2 degrees higher than the 90 degree span of injection. Decreasing cavity length improved thrust ratio and discharge coefficient, but decreased thrust vector angle and thrust vectoring efficiency. Increasing cavity convergence angle from 20 to 30 degrees increased thrust vector angle by 1 degree over the range of injection rates tested, but adversely affected system thrust ratio and discharge coefficient. The dual throat nozzle concept generated the best thrust vectoring performance with an expansion ratio of 1.0 (a cavity in between two equal minimum areas). The variable expansion ratio geometry did not provide the expected improvements in discharge coefficient and system thrust ratio throughout the flight envelope of typical a supersonic aircraft. At mid-climb and cruise conditions, the variable geometry design compromised thrust vector angle achieved, but some thrust vector control would be available, potentially for aircraft trim. The fixed area, expansion ratio of 1.0, Dual Throat Nozzle provided the best overall compromise for thrust vectoring and nozzle internal performance over the range of NPR tested compared to the variable geometry Dual Throat Nozzle.
\end{abstract}

\footnotetext{
${ }^{*}$ Aerospace Engineer, Configuration Aerodynamics Branch, Mail Stop 499, AIAA Associate Fellow.

$\dagger$ Aerospace Engineer, Configuration Aerodynamics Branch, Mail Stop 499, AIAA Senior Member.

\$ Aerospace Engineer, Configuration Aerodynamics Branch, Mail Stop 499.

$\S$ Aerospace Engineer, Configuration Aerodynamics Branch, Mail stop 499, AIAA Fellow.

${ }^{* *}$ Aerospace Engineer, Advanced Aerospace Systems Branch, Mail Stop 411.
} 


\section{Nomenclature}

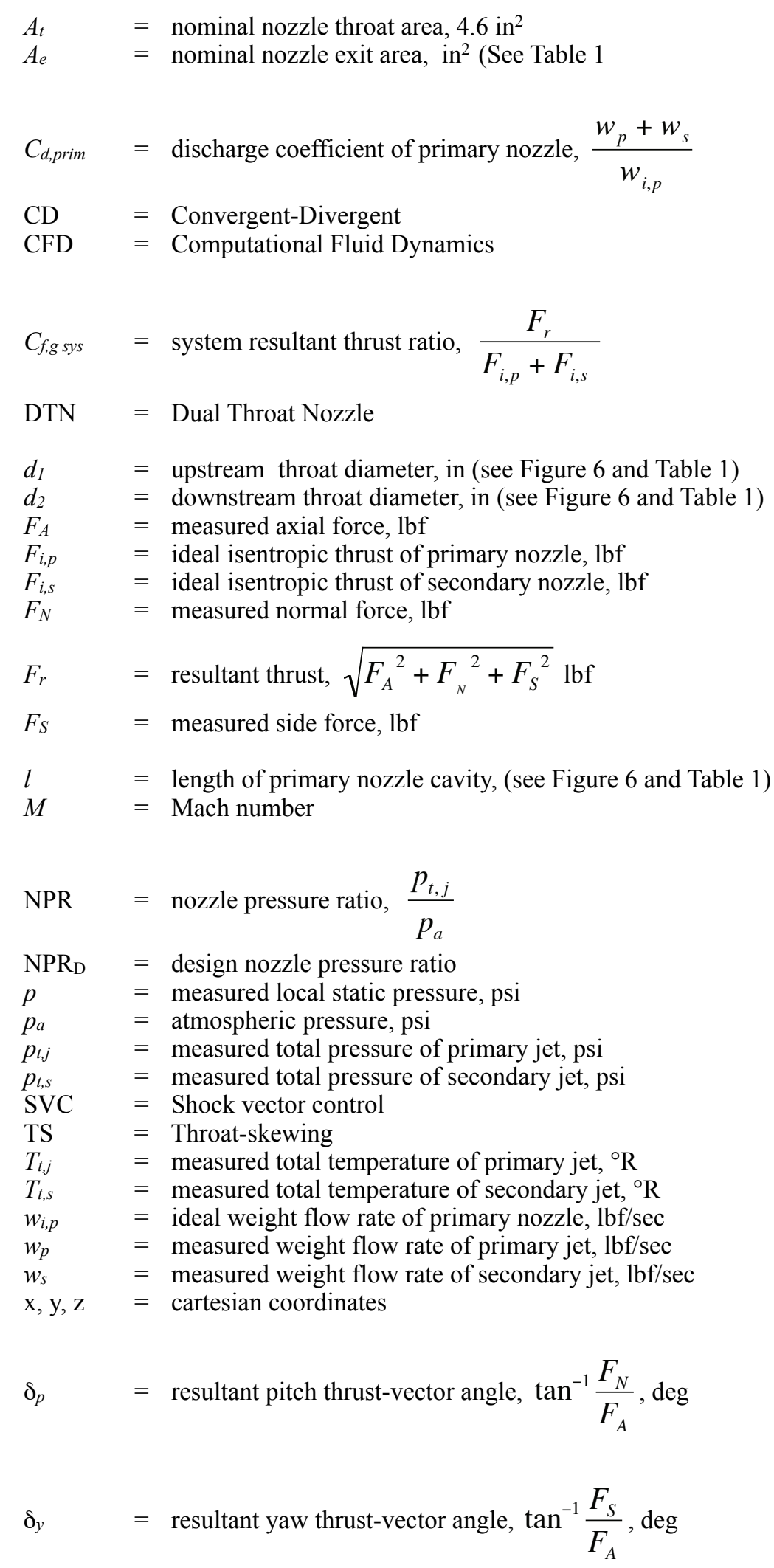


$\theta_{1} \quad=$ upstream divergent cavity ramp angle, deg (see Figure 6)

$\theta_{2}=$ downstream convergent cavity ramp angle, deg (see Figure 6)

$\phi \quad=$ secondary flow injection angle, $150 \mathrm{deg}$ (see Figure 6)

\section{Introduction}

\section{A. Background}

Thrust vectoring is a candidate control effector with potential to augment conventional actuators for take-off and landing requirements of future supersonic aircraft with low sonic-boom signatures. Reduced aircraft sonic-boom signatures are partially accomplished by tailoring of the airplane lift distribution. Integration of thrust vectoring nozzles with a canard airframe configuration may optimize specific tailoring of the lift distribution during cruise, resulting in sonic-boom signatures significantly lower than conventional configuration signatures. Additionally, thrust vectoring could provide control power for trimming the aircraft and reduce cruise trim drag. Thrust vectoring is an extremely powerful and valuable control effector at low dynamic pressures, where traditional aerodynamic control technologies loose control power. There are two ways to accomplish thrust vectoring, fluidic and mechanical. Fluidic thrust vectoring systems offer the design advantage of fewer moving parts, which have the potential for substantial weight reductions compared to mechanical thrust vectoring nozzles. Mechanical thrust vectoring nozzles require actuated hardware to direct the exhaust flow off-axis. Nozzles used on supersonic aircraft, will require a variable area nozzle (either fluidic or mechanical) to achieve optimal performance throughout the flight envelope.

Fluidic thrust vectoring is the manipulation or control of the exhaust flow with the use of a secondary air source, typically bleed-air from the engine compressor or fan. Three primary mechanisms of fluidic thrust vectoring have been studied over the last 15 years: shock-vector control, throat shifting, and counterflow (refs. 1-14). These techniques can be used to vector the exhaust flow in the pitch or yaw direction. In an effort to evaluate the thrust vectoring efficiency $(\eta)$ of a configuration, the thrust vector angle in degrees $\left(\delta_{p}\right.$ or $\left.\delta_{y}\right)$ is normalized by the percent of secondary fluidic injection. The thrust vectoring efficiency parameter facilitates evaluation and comparison of different configurations or techniques using different amounts of secondary injection. Finally, system thrust ratio $C_{f, g}$ sys is defined as the ratio of resultant thrust to the sum of ideal thrust of the primary and secondary flows and is used to evaluate the thrust efficiency of fluidic thrust vectoring nozzles.

The Dual Throat Nozzle (DTN) concept, shown in figure 1, is currently being researched at NASA Langley Research Center (LaRC). The original DTN is designed with two minimum areas, an upstream minimum and a downstream minimum at the nozzle exit $\left(A_{e} / A_{t}=1.0\right)$ with a cavity in between the upstream throat and exit. The Dual Throat Nozzle design enhances the throat shifting method of thrust vectoring using fluidic injection at the upstream minimum area to control separation and maximize pressure differentials in the cavity. In the non-vectoring mode, no fluidic injection occurs and the sonic line or 'throat' of the nozzle lies at the nozzle exit minimum area. In the thrust-vectoring mode, asymmetric fluidic injection is introduced at the upstream minimum area, causing a skewed sonic line upstream of the exit and an increased pressure differential along the recessed cavity walls. A supersonic jet requires a variable area nozzle that can adjust to take-off conditions, and be optimized for cruise. To do so, the DTN nozzle would likely have a variable geometry allowing the expansion ratio to change throughout the flight envelope to optimize thrust ratio.

Researchers at NASA LaRC have computationally guided the design (refs. 15 and 16) using the unsteady Reynolds-Averaged Navier-Stokes flow solver PAB3D. A two-dimensional (rectangular-shaped) dual throat nozzle was experimentally demonstrated (refs. 17 \& 18) in the NASA LaRC Jet Exit Test Facility, to achieve larger thrust vectoring efficiencies than the traditional throat shifting method, without compromising the system thrust ratio (figure 2). Figure 2 presents a comparison of experimental data for the two-dimensional rectangular (DTN: 2D) and the axisymmetric (DTN: AXI) dual throat nozzles compared with other concepts employing the throat shifting (TS) and shock vector control (SVC) concepts that have been published in references 1-9 and 18. The dual throat nozzle concepts produce substantially larger thrust vectoring efficiencies than the other concepts over the entire range of NPR. Additionally, the axisymmetric and the $2 \mathrm{D}$ rectangular geometries produce approximately equivalent thrust vectoring efficiencies over the range of NPR. The $2 \mathrm{D}$ rectangular geometry has higher thrust ratios for NPR $<6$ than 
the axisymmetric DTN, but the thrust ratios are equivalent for NPR $=6$ and above. The 2D DTN has higher thrust ratios than all the nozzles listed for NPR $<8$, but was approximately $1 \%$ lower than two shock vector control nozzles that were designed for higher NPR's.

After successfully predicting performance trends on the rectangular DTN, PAB3D was used to guide the computational design of the axisymmetric DTN concept. The details of the computational study on the axisymmetric DTN concept are presented in reference 19, which includes predictions of the DTN variable area nozzle at various flight conditions with NPR up to 10 and Mach numbers up to 2 . In the current investigation, the experimental nozzle performance at static free-stream conditions for the axisymmetric DTN concept will be presented, as well as some comparisons between experimental and computational data. The axisymmetric DTN concept had fluidic injection introduced through a portion of the circumference of the nozzle at the upstream minimum area for thrust vectoring mode. In an actual flight vehicle, pitch thrust vectoring could be implemented by using top or bottom injection plenums (figure 3(a)), while yaw thrust vectoring, if needed as a control effector, would be implemented by using right or left injection plenums (figure 3(b)). The computational results were used to define the set of axisymmetric stereo lithography nozzle models that were fabricated for experimental testing (Table 1). Figure 4 shows a CAD image of an axisymmetric DTN model and figure 5 shows a photograph of a stereo lithography model of an axisymmetric DTN mounted to the propulsion simulation system in the Jet Exit Test Facility at NASA LaRC. The nozzle geometric design variables (shown in figure 6 and Table 1) that will be discussed include: expansion ratio $\left(A_{e} / A_{t}\right)$ for conditions corresponding to take-off and landing, mid-climb and cruise; cavity convergence angle $\left(\theta_{2}\right)$; cavity length $(l)$, and circumferential span of injection (figure 7$)$. Data were collected at nozzle pressure ratios (NPR) from 1.89 to 10 with injection rates from no injection (unvectored case) to $4 \%$ of the primary flow rate at NPR 10 and $10 \%$ at NPR 1.89 , all at free-stream static conditions $(M=0)$.

\section{B. Variable Geometry Nozzle}

As seen in a previous study of the 2D DTN concept (ref. 16), the DTN provides the largest vectoring efficiencies at $A_{e} / A_{t}=1$ which is appropriate for take-off and landing. When applied to a supersonic vehicle the nozzle exit area would have to vary and open for optimal thrust efficiency throughout the flight envelope. Figure 8 presents a notional variable geometry nozzle operating curve for a supersonic aircraft. Curves A, B and C represent operating curves for fixed nozzle designs at various expansion ratios. Curve D represents the operating curve for a variable geometry nozzle. Numbers on the thrust ratio versus NPR curve represent operating points to be discussed below. At low Mach number and low NPR a low nozzle expansion ratio is required for peak performance in terms of thrust ratio. Curve $\mathrm{A}$ is representative of a low expansion ratio nozzle designed for optimum performance at take-off and landing conditions (point 1). As Mach number and NPR increase the expansion ratio must also increase to maintain optimum efficiency. As expansion ratio increases, the nozzle operating curve shifts to the right (curves B and C) and peaks at a higher NPR (point 2 for a medium expansion ratio nozzle and point 3 for a higher expansion ratio nozzle). With a fixed nozzle design it is only possible to design for one optimum point in the flight envelope: takeoff/landing (curve A, point 1); mid-climb (curve B, point 2); or cruise (curve C, point 3). One might consider a compromise by designing a fixed geometry nozzle with a medium expansion ratio in order to keep the nozzle complexity and weight to a minimum. The delta between points 1 and 4 indicates the performance penalty a medium expansion ratio nozzle would have at take-off and landing conditions versus a low expansion ratio nozzle. The delta between point 3 and point 5 is indicative of the penalty a low expansion nozzle would exhibit at cruise conditions where a high expansion ratio nozzle is more efficient. By using a variable expansion ratio nozzle (curve D) it is possible to operate the nozzle at the peak efficiency throughout out the flight envelope (points 1,2 and 3).

CFD studies indicate that the DTN concept loses vectoring efficiency as area ratio increases, but it may provide adequate thrust vectoring for aircraft trim at higher expansion ratios. To apply the DTN concept to a supersonic aircraft it is necessary to vary the nozzle exit area (and hence expansion ratio). To accomplish this, the nozzle would have a variable geometry with a hinge at the cavity apex in order to increase expansion ratio as NPR increases. Data for several NPR's and area ratios will be presented for take-off and landing, mid-climb and cruise.

\section{Apparatus and Experimental Methods}

The study was conducted in the NASA LaRC Jet Exit Test Facility. This section discusses the test facility, dualflow propulsion system, model hardware, instrumentation, and computational method.

\section{A. Jet Exit Test Facility}

The Jet Exit Test Facility is an indoor reduced-scale pressurized-air test stand combining multi-flow propulsion simulation with high-pressure and high flow-rate capabilities. This facility is typically used to test nozzle internal performance at static (no external flow) conditions. A continuous supply of clean, dry high-pressure air is delivered from a central $5000 \mathrm{psi}$ compressor station. The high-pressure air supply is reduced to feed two independently controlled $1800 \mathrm{psi}$ air lines which supply the test model. The air control system is similar to that of the Langley 16 - 
Foot Transonic Tunnel (ref. 20) but has been enhanced by the installation of settling tanks after the 5000 psi reduction and by the addition of bypass regulation systems (for precise low-flow and high-flow settings) and dual flow-control valves after regulation. Pressurized air from one or both supply lines is directed through a singleengine simulation system to the test nozzle, to a large test bay area, and vented to atmosphere through two sets of acoustically-treated ceiling ducts.

\section{B. Dual-flow Propulsion Simulation System}

The dual throat nozzle fluidic thrust vectoring nozzle model was tested on the facility dual-flow propulsion simulation system. The test rig is an axisymmetric single-engine propulsion simulator with dual co-annular ducts mounted on a six-component strain-gauge balance (NASA LaRC Balance 1636). An 1800 psi air line supplies each of the model plenums: the core flow (primary) plenum and the outer annular (secondary) plenum. Each supply line is instrumented with a multiple critical venturi system (ref. 21). The facility is capable of flow rates up to $25 \mathrm{lb} / \mathrm{sec}$ per supply line and incorporates a steam heat exchanger to maintain nozzle and secondary total temperatures near $75^{\circ} \mathrm{F}$. In the simulator, the high-pressure air transitions from the non-metric part to the metric (supported by the balance) part of the test rig through semi-rigid, stainless-steel, 'S' shaped tubes (S-tubes). The S-tubes (two per flow path) are designed to minimize the balance tares and axial momentum transfer caused by the high-pressure air crossing the metric/non-metric break on the test rig. The primary (nozzle) air supply passes from the core plenum to an annular duct located on the test-stand centerline through eight radially spaced sonic nozzles. The flow then passes through a circular duct and a choke plate (flow-straightener) before entering the circular instrumentation section. From the instrumentation section, the flow then enters the primary nozzle. To supply the nozzle secondary injection plenum, the test rig nominal secondary flow path was blocked to pressurize the test rig secondary plenum. A high-pressure flexible hose was used to connect the test rig secondary plenum to a remote-control valve located on the lower portion of the nozzle model. This valve provided final control of the air entry to the nozzle model secondary flow injection plenum.

\section{Model Description}

A photograph of a dual throat nozzle installed in the test facility is shown in Figure 5. The model is an axisymmetric convergent-divergent-convergent primary nozzle with two geometric minimum areas. The sketch of the model shown in figure 6 illustrates the nozzle design variables. The design incorporates a cavity between the two minimum areas. The nozzle models were fabricated using stereo-lithograph. A separate nozzle model was built and tested for each geometric variation. Nozzle model geometric variables are defined in Table 1. The upstream nominal throat diameter was, $d_{l}=2.42$ inch with a nominal upstream throat area of $A_{t}=4.6$ square inches. The nozzle area ratios tested were $A_{e} / A_{t}=1,1.48$ and 1.93 which correspond to $N P R_{D}=1.89,6$, and 10 , respectively. The cavity lengths tested were $l=5.26$ and 4.21 inches. The divergent cavity ramp angle was $\theta_{l}=-10$ degrees for all configurations tested. The convergent cavity ramp angles, $\theta_{2}$, tested ranged from 11 to 30 degrees. The secondary flow was injected at the upstream minimum area. Two different circumferential spans of secondary injection were tested: 60 degrees and 90 degrees (Figures $7 \mathrm{a}$ and $7 \mathrm{~b}$ ). Both injection spans had the same total open area of 0.0798 square inches and consisted of 12 individual injection ports distributed evenly in either a 60 deg or 90 degree arc around the nozzle upstream throat. The configuration numbers have a -60 or -90 appended when referenced throughout the report to indicate the span of the secondary injection arc. The secondary flow injection holes had a diameter of 0.0920 inches. The secondary flow injection angle, $\phi$, was 150 degrees for all configurations presented (see figure 6).

\section{Instrumentation}

Forces and moments on the model were measured using a six-component strain gauge balance (NASA balance 1636). The maximum capacity and estimated accuracy for each balance component are listed in Table 2 . Since the model was axisymmetric ((with the exception of the secondary injection ports), significant rolling moment, yawing moment, and side force measurements were not expected.

The model was instrumented with up to 56 surface static pressure taps on the centerline of the upper and lower internal surface of the primary nozzle. The taps were spaced approximately every 0.4 inch starting at 0.6 inch upstream of the upstream-nozzle throat extending to the nozzle exit (or downstream throat). The model static pressures were measured using electronic pressure transducers with a range of $250 \mathrm{psid}$, as determined by expected pressure maximums. The accuracy of the electronic pressure transducers as given by the manufacturer was \pm 0.1 percent of full scale.

The primary jet total pressure, $p_{t, j}$, was obtained by mounting a single rake of eight Pitot probes in the instrumentation section upstream of the primary nozzle. The pressures were measured by using individual pressure transducers with a range of 500 psid with an accuracy \pm 0.1 percent of full scale. The eight individual readings were then averaged with an area weighting assigned to each probe to obtain $p_{t, j}$. The primary jet total temperature, $T_{t, j}$, 
was the computed average of measurements from two individual thermocouples also mounted in the instrumentation section. The accuracy of the thermocouple as given by the manufacturer was $\pm 4{ }^{\circ} \mathrm{F}$. The secondary air total pressure, $p_{t, s}$, was measured by a single Pitot probe located in the injection block plenum using an individual 500 psid pressure transducer with an accuracy of \pm 0.25 percent of full scale. The secondary total temperature, $T_{t, s}$, was measured by a single thermocouple located in the union between the flexible hose line feeding secondary air to the model and the injection block. The accuracy of the thermocouple as given by the manufacturer was $\pm 4^{\circ} \mathrm{F}$. The ambient pressure, $p_{a}$, was measured with a 15 psia pressure transducer with an accuracy of \pm 0.03 percent of reading (sea-level barometric pressure).

The weight flow rates of the air supplied to the primary nozzle and the secondary injection plenum were measured by a pair of multiple critical venturi systems located upstream of the propulsion simulation system. The multiple critical venturi's have been calibrated to an accuracy of 0.1 percent of reading. Reference 21 describes the multiple critical venturi system in further detail.

\section{E. Computational method}

The computational fluid dynamics (CFD) code PAB3D was used to guide the experimental nozzle design (refs. 15,16 and 19). PAB3D was chosen for this nozzle work because it was originally developed as an internal flow propulsion code and has been well tested and documented for predicting complex flow features in aeropropulsive, as well as aerodynamic configurations (refs. 22 to 35). Additionally, PAB3D successfully predicted internal nozzle performance trends of the 2D rectangular DTN (reference 16 and 18).

PAB3D requires a structured-mesh computational domain. A multiblock (ref. 23) feature allows the domain to be partitioned into sections, which is critical for modeling complex configurations and for efficiently running the parallel version of PAB3D. The implicit, finite-volume flow solver represents the three-dimensional, unsteady unsteady Reynolds-averaged Navier-Stokes (URANS) equations. Several advanced turbulence models (refs. 30 to 33) are available for closure of the URANS equations. PAB3D is third-order accurate in space and second-order accurate in time. PAB3D has the capability to simulate time-varying boundary conditions for pulsed injection applications (ref. 34). Details of the computational study used to guide selection of the experimental test parameters can be found in reference 19 .

\section{Results and Discussion}

\section{A. Nozzle Performance without Secondary Injection}

Figure 9 presents the baseline nozzle (configuration 13-60) internal performance without secondary injection across the NPR range tested. Data for a typical convergent nozzle are also presented for reference. The area ratio for this configuration was $A_{e} / A_{t}=1.0$ which corresponds to $\mathrm{NPR}_{\mathrm{D}}=1.89$. As observed in previous studies of the 2D $\mathrm{DTN}$, thrust ratio, $C_{f, g}$ sys, peaked at approximately NPR $=3$ instead of near $\mathrm{NPR}_{\mathrm{D}}=1.89$ as would be expected for a typical convergent nozzle (refs. 17 and 18). With increasing NPR, $C_{f, g}$ sys decreased almost linearly to approximately 0.93 as the nozzle becomes highly under-expanded. Nozzle discharge coefficient was generally flat and $C_{d, p r i m} \approx 0.926$ at NPR $>3$. Thrust vector angle, $\delta_{p}$, was not zero as expected with no secondary injection. Thrust vector angle was $\delta_{p}=4.5 \mathrm{deg}$ at NPR $=1.89$ and then decreased to ultimately flatten out at $\delta_{p} \approx 1.5 \mathrm{deg}$ as NPR increased above 3. While the data presented in Figure 9 is without secondary flow injection, the nozzle was run with the secondary injection ports present, but valved closed to prevent flow entrainment from the secondary airline. The presence of the injection ports which spanned 60 degrees around the circumference of the nozzle at the upstream minimum area, created an asymmetric disturbance at the upstream throat which may have caused a separation in the nozzle and vectored the primary jet. Other nozzle configurations tested showed a smaller positive offset in $\delta_{p}$ (generally less than 2 degrees) at NPR $<3$, but generally approached $\delta_{p}=0$ deg at higher NPR's indicating that there may have also been a small geometric asymmetry in configuration 13-60. The flagged symbols in figure 9 represent data taken with decreasing NPR to investigate the presence of hysteresis. The nozzle did not exhibit any significant hysteretic effects.

The thrust ratio and discharge coefficient performance near design $\left(\mathrm{NPR}_{D}=1.89\right.$ for $\left.A_{e} / A_{t}=1.0\right)$ for the current DTN configuration (cavity between $A_{t}$ and $A_{e}$ ) are lower than would be expected for a typical non-thrust vectoring convergent nozzle design with no cavity $\left(C_{f, g s y s}\right.$ and $\left.C_{d, p r i m} \approx 0.99\right)$. Because the cavity is always present in the DTN design, even when no-thrust vectoring is required, the performance penalty would preclude use of the DTN unless thrust-vectoring was an overriding mission requirement of the aircraft.

Figure 10 presents the nozzle internal performance for a family of nozzles with varying area ratio without secondary injection. Each nozzle in the group is representative of a different expansion ratio appropriate for a different NPR in the flight envelope. Configurations 13-60, 15-60, and 14-60 represent a variable geometry DTN nozzle at three design conditions. Configuration 13-60 is a low expansion ratio nozzle appropriate for take-off and 
landing conditions, $A_{e} / A_{t}=1.0\left(\mathrm{NPR}_{\mathrm{D}}=1.89\right)$. Configuration $15-60$ is representative of a medium expansion ratio, $A_{e} / A_{t}=1.48\left(\mathrm{NPR}_{\mathrm{D}}=6\right)$ and would operate on design at $\mathrm{M} \approx 1.4$. This mid-expansion ratio nozzle was selected for testing, but any expansion ratio between 1.0 and 10.0 would be possible for the current design. Configuration 14-60 has the maximum expansion ratio tested of $A_{e} / A_{t}=1.93\left(\mathrm{NPR}_{\mathrm{D}}=10\right)$ and operates on design at $\mathrm{M} \approx 2.0$ (supersonic cruise). These nozzle expansion ratios would be indicative of the notional nozzles A, B, and C in figure 8 , respectively. In figure 10 , one can compare the performance of a fixed geometry nozzle by following the data of one configuration over the range of NPR, to the performance of a variable geometry nozzle by using one data point at each NPR from the configuration with that NPR $\mathrm{D}_{\mathrm{D}}$. The thrust ratio for configuration 13-60 peaked at approximately NPR $=3$ and then decreased linearly with increasing NPR. It crosses the curve for configuration 14-60 at approximately NPR $=8.4$. At NPR $>8.4$ configuration $14-60$ becomes more thrust efficient and peaks near $\mathrm{NPR}_{\mathrm{D}}=10$ (maximum NPR tested) with $C_{f, g}$ sys $=0.944$ which is a $1.4 \%$ improvement versus configuration $13-60$ $\left(C_{f, g}\right.$ sys $=0.930$ at $\left.\mathrm{NPR}=10\right)$. The thrust ratio for configuration $15-60$ with $\mathrm{NPR}_{\mathrm{D}}=6$ peaked at $\mathrm{NPR}=8$ with $C_{f, g}$ sys $=0.914$. This was approximately $2 \%$ and $3 \%$ lower than configurations $14-60$ and $13-60$, respectively, indicating the mid expansion ratio configuration did not offer any thrust performance benefits, even at NPR $=6$ where a benefit was expected (see figure 8).

CFD predictions are shown in in figure 10 as solid symbols. The computational results predicted the same trends for $C_{f, g}$ sys and $C_{d, p r i m}$ as experiment, with a fair prediction of magnitudes. Further insight is provided by looking at the flow characteristics inside the nozzle. Figures 11 to 13 present computational Mach contours inside the nozzle at nozzle pressures ratios of $1.89,6$ and 10 respectively. In figures 11 to 13 , one can compare the performance of a fixed geometry nozzle by following the data of one configuration over the range of NPR (horizontal comparisons across the page), to the performance of a variable geometry nozzle by using one data point at each NPR from the configuration with that $\mathrm{NPR}_{\mathrm{D}}$ (diagonal comparison across the page of Fig 11(a), Fig 12(b) and Fig. 13(c)). For example, flow throughout the DTN configuration (13-60) was subsonic at NPR=1.89, while nozzles $15-60$ and 14-60 were over-expanded at NPR=1.89 with internal shock and separation losses (figure 11). This exemplifies the benefit of a variable geometry nozzle for a supersonic aircraft, such that configuration 14-60 was designed and performed best at cruise $\left(\mathrm{NPR}_{\mathrm{D}}=10\right)$, while the take-off and landing configuration (13-60) provided a thrust ratio $18 \%$ higher than configuration $14-60$ at NPR=1.89. Unexpectedly, configuration $14-60$ had better performance than configuration 15-60 at both $\mathrm{NPR}=6$ and 10 (figure 10). At NPR=6 with no injection, configuration 15-60 has a normal shock, Mach disk inside the nozzle with flow completely separated from the divergent walls in the cavity (figure 12(b)), resulting in large thrust ratio losses (figure 10). At NPR $=6$, the flow in configuration 14-60 continues to expand through the nozzle with oblique shocks at the cavity apex (figure 12(c)), causing losses in the nozzle. Therefore, the performance of configuration 14-60 was only slightly better than configuration 15-60 at $\mathrm{NPR}=6$. As NPR increases to 10 (figure 13), there is very little change in the flow features within each nozzle. This is further evidenced in the experimental pressure distributions of configuration 13-60, 15-60, and 14-60 shown in figure 14 (Note: There is no pressure measurement on the lower surface at $x / l=0$ due to the presence of the secondary injection holes. Therefore, the curve faring is erroneous in this location on figure 14). At NPR $>3$, there were minimal changes in the pressure distributions with increasing NPR for any of the nozzles. The pressure distribution shown in figure 14 indicate that shock induced separation occurs further upstream in configuration 15-60 than in configuration 14-60 at all NPR tested; this result helps to explain the poor performance of configuration 15-60. The computational flow contours demonstrate the differences that occurred downstream of the nozzle exit in the plume as the flow adjusted to the increase in NPR, through expansion of the flow in the plume (compare configuration 15-60 in figures 12(b) and 13(b), or configuration 14-60 in figures 12(c) and 13(c)).

\section{B. Effect of Circumferential Span of Secondary Injection}

Previous studies of the DTN concept investigated 2D-rectangular nozzle concepts in which the secondary injection spanned the width of the nozzle (refs. 15 to 18). In the computational study of the axisymmetric DTN three injection spans were studied: 45,60 and 90 degrees. It was concluded that the 60 -degree span of injection provided the best compromise between thrust vectoring performance, thrust ratio and discharge coefficient (ref. 19). To verify the computational results, two injection spans were tested in the experimental study, 60 and 90 degrees on the baseline configuration $13\left(\mathrm{NPR}_{\mathrm{D}}=1.89\right)$, referred to as configurations 13-60 and 13-90, respectively (Table 1).

Figure 15 presents the experimental data on the effect of injection span on nozzle internal performance at NPR $=1.89$. Computational data with 3 percent secondary injection are also presented as solid symbols for comparison. Both configurations had positive pitch vector angle with no secondary injection $\left(w_{s} /\left(w_{i, p}+w_{s}\right)=0\right)$, indicating a possible separation in the nozzle caused by the presence of the secondary injection orifices. The 60 degree injection span generally performed better in terms of thrust vector angle and thrust ratio. Configuration 13-60 achieved pitch vector angles approximately 1.5 to 2 degrees higher than the configuration 13-90 for secondary injection rates less than 7 percent. Consequently, the thrust vectoring efficiency was also generally higher for configuration 13-60. Unless extreme thrust vectoring requirements are needed, it is expected that secondary 
injection rates will be limited to values less than $5 \%$ for most applications. At secondary injections rates above 7\%, configuration 13-90 performed better in terms of $\delta_{p}$ and $C_{f, g} s y s$. The maximum pitch vector angle achieved by configuration 13-60 was $\delta_{p}=19.8$ degrees at a secondary injection rate of 6 percent. Thrust ratio generally followed similar trends for both configurations, decreasing with increasing secondary injection rate. Between injection rates of 2 and 6 percent, the thrust ratio for configuration 13-60 was higher by 0.014 at 5\% secondary injection. Nozzle discharge coefficient also followed similar trends for both configurations, decreasing with increasing secondary injection rate. Primary nozzle discharge coefficient for configuration 13-60 showed a slight increase over configuration 13-90 at injection rates between 2 and 6 percent. The decrease in discharge coefficient with increasing secondary injection rate is a concern of the DTN concept in that engine operability could be adversely affected (this trend is also evident in previous 2D results reported in references 17 and 18). A decrease in discharge coefficient of this magnitude could result in the requirement for a variable throat area adding complexity and weight to the nozzle.

The computational data at $3 \%$ secondary injection rate was generally optimistic in predicting $\delta_{p}, C_{f, g}$ sys and $\eta$, but under-predicted $C_{d, p r i m}$. The improvement of 1.5 to 2 degrees in $\delta_{p}$ at secondary injection rates less than $7 \%$ seen for configuration 13-60 may in part be a result of the initial offset from $\delta_{p}=0$ with no secondary injection (discussed previously for this configuration in section III(A)).

Figure 16 presents the effect of injection span angle in terms of $\Delta \delta_{p}$ which removes the offset of $\delta_{p}$ from $\delta_{p}=0$ with no secondary injection. Configuration 13-60 still performs slightly better than configuration 13-90 at secondary injection rates less than $6 \%$, but the difference is minimal. At secondary injection rates above $6 \%$, configuration $13-90$ vectors more effectively by as much as 3 degrees at $10 \%$ secondary injection.

\section{Effect of Cavity Length and Convergence Angle with Secondary injection}

The effects of cavity length on nozzle performance and thrust vectoring were investigated to determine if a shorter nozzle, for reduced propulsion system weight, could generate the same levels of thrust efficiency and thrust vectoring efficiency. Also, the effects of cavity convergence angle were investigated with the shorter nozzle $(l=4.2$ inch).

The computational study indicated that shortening the nozzle would have a positive impact on thrust ratio and discharge coefficient with a small negative impact on thrust vectoring efficiency (ref. 19). As seen previously, the computational predictions were generally optimistic compared to the experimental results, but generally indicated the trends seen experimentally. Figure 17 presents the effect of cavity length on nozzle internal performance at design NPR $=1.89$ with varying secondary flow injection rates for configurations $13-60$ and 25-60 with cavity lengths $l=5.26$ inch and $l=4.21$ inch, respectively (Table 1). As observed in the computational study of the axisymmetric nozzle and previous studies of the two-dimensional dual throat nozzle (ref. 17), the shorter cavity length had a detrimental effect on the thrust vector angle achieved and the thrust vectoring efficiency at secondary injection rates less than $8 \%$. However, the negative impact was more pronounced than predicted computationally. At $3 \%$ secondary injection, the predicted decrease in thrust vectoring efficiency was $0.5 \%$-injection (from $\eta=5.5 \% \%$-injection to $\eta=5.0 \% \%$-injection between the long and short cavities, respectively). Experimentally, the decrease in thrust vectoring efficiency was $0.9^{\circ} \%$-injection (with $\eta=5.2^{\circ} \%$-injection for the long cavity and $\eta=0.3 \%$-injection for the short cavity). In agreement with the computational study, the shorter cavity length axisymmetric nozzle improved the thrust ratio compared with the longer cavity nozzle, but the improvement was more significant experimentally. At 3\% secondary injection, thrust ratio increased from 0.937 to 0.940 computationally and from 0.919 to 0.928 experimentally. The improvement in nozzle discharge coefficient from the long cavity to the short cavity was typically less than $1 \%$ across the range of secondary injection ratios tested. The computational study indicated a slightly larger improvement in nozzle discharge coefficient of approximately $2 \%$.

Previous studies of the 2D DTN (ref. 18) and the axisymmetric nozzle (ref. 19) indicated that increasing the cavity convergence angle, $\theta_{2}$, had a positive impact on vector angle and vectoring efficiency with a minimal negative impact on thrust efficiency and nozzle discharge coefficient; the computational study indicated a slight improvement in thrust efficiency by increasing the cavity convergence angle. Two cavity convergence angles were tested, $\theta_{2}=20^{\circ}$ and $30^{\circ}$, for the nozzle length, $l=4.21$ inch The effect of cavity convergence angle on internal nozzle performance at NPR $=1.89$ is presented in figure 18. The experimental nozzle internal performance data for the axisymmetric nozzle generally followed the trends seen for the 2D nozzle (ref. 18). Pitch vector angle, $\delta_{p}$, was improved by approximately one degree across the range of secondary injection rates tested by increasing the cavity convergence angle. Thrust vectoring efficiency was also slightly improved with the effect decreasing at higher secondary injection rates. Nozzle discharge coefficient, $C_{d, p r i m}$, was adversely affected by increasing the cavity convergence angle. The adverse effect on nozzle discharge coefficient increased with increasing secondary injection rate. At $3 \%$ secondary injection, the nozzle discharge coefficient decreased by $3.1 \%$. At $8 \%$ secondary injection, the decrease in $C_{d, p r i m}$ was $3.8 \%$. The thrust efficiency, $C_{f, g}$ sys, was adversely affected by increasing convergence 
angle, in agreement with previous $2 \mathrm{D}$ studies, but contrary to the current computational study which indicated a slight increase.

\section{Baseline Nozzle Performance with Secondary Injection at NPRD}

Figure 19 presents the internal performance with secondary injection of the family of nozzles (discussed above in section III(A)) that includes configurations 13-60, 15-60, and 14-60 at their respective $\mathrm{NPR}_{\mathrm{D}}$ (i.e. sized appropriately for three points in a notional flight envelope seen in figure 8). Configuration 13-60 data are presented at $\mathrm{NPR}_{\mathrm{D}}=1.89$. Configuration 15-60 data are presented at $\mathrm{NPR}_{\mathrm{D}}=6$ and Configuration 14-60 data are presented at $\mathrm{NPR}_{\mathrm{D}}=10$ in figure 19 .

Configuration 13-60 has the best thrust vectoring performance across the range of secondary injection rates tested as expected from previous studies (refs. 15 to 18). Peak thrust vector angle of $\delta_{p}=19.8$ degrees was achieved at 6 percent secondary injection. The peak thrust ratio was $C_{f, g} s y s=0.97$ with no injection and then decreased with increasing secondary injection rate. Similarly, nozzle discharge coefficient was maximum with no injection, $C_{d, p r i m}=0.893$, and decreased with increasing secondary injection rate as the secondary jet aerodynamically reduced the effective throat area.

The maximum thrust vector angle achieved for configuration $15-60$ was $\delta_{p}=4.5^{\circ}$ at 5 percent secondary injection and $\delta_{p}=2.3^{\circ}$ at 4 percent secondary injection for configuration 14-60. The maximum secondary flow injection rates for these configurations and NPR's were limited due to model pressure limitations. The pitch vector angle generally increased with increasing secondary flow ratio for these configurations. The peak thrust ratio for these configurations occurred with no secondary injection. Although the measured thrust vector angles for configurations 14-60 and 15-60 were small, only a limited amount of thrust vectoring would be needed at supersonic speeds (possibly for trim control).

\section{E. Effect of Nozzle Expansion Ratio with Secondary Injection}

The effects of a variable expansion ratio nozzle on vectored nozzle performance were investigated over a typical Mach and NPR range of a supersonic aircraft. The effects of a variable expansion ratio are shown in the comparison of figures 20 and 21. Nozzle performance for the fixed geometry dual throat nozzle with $A_{e} / A_{t}=1.0$ (configuration 13-60) operating over a range of NPR with 3\% fluidic injection is shown in figure 20 . Nozzle performance of a variable expansion ratio nozzle over a range of NPR with 3\% injection (configurations 13-60, 15-60, 14-60) with increasing expansion ratios from $A_{e} / A_{t}=1.0$ to $A_{e} / A_{t}=1.93$ is shown in figure 21. Each data point in figure 21 (both computational and experimental) represent a unique nozzle expansion ratio optimized for a given NPR as discussed in section III(A) and are representative of the notional operating curve of the variable geometry nozzle $\mathrm{D}$ in figure 8 . The data are compared to computational results from reference 19 , computed with static free-stream conditions. The computational data generally gave a very good indication of the trends seen in the experimental data. The computational estimates were generally optimistic in predicting thrust vector angle and system thrust ratio and pessimistic in predicting nozzle discharge coefficient. Secondary air was injected through a series of holes as described in section $\mathrm{II}(\mathrm{C})$, whereas the computational model simulated the secondary injection through a slot. The difference in the slot geometry between experiment and CFD may account for some of the differences between the experimental data and the predictions.

As expected, the fixed geometry DTN configuration (13-60, $\left.A_{e} / A_{t}=1.0\right)$ performed significantly better in terms of thrust vector angle achieved across the NPR range (figure 20(a)) compared to the variable expansion ratio nozzle (figure 21(a)). The DTN nozzle achieved maximum thrust vector angle of $\delta_{p}=15.7^{\circ}$ at $\mathrm{NPR}_{\mathrm{D}}=1.89$ with $3 \%$ secondary flow injection. The thrust vector angle decreased to $\delta_{p}=11.0^{\circ}$ at NPR $=6$ and $\delta_{p}=10.2^{\circ}$ at NPR $=10$. As the expansion ratio of the nozzle was increased (figure $21(\mathrm{a})$ ) from a DTN configuration $\left(A_{e} / A_{t}=1.0\right)$ at $\mathrm{NPR}_{\mathrm{D}}=1.89$, to $A_{e} / A_{t}=1.476$ at $\mathrm{NPR}_{\mathrm{D}}=6$ and $A_{e} / A_{t}=1.928$ at $\mathrm{NPR}_{\mathrm{D}}=10$, the thrust vector angle decreased significantly to $\delta_{p}=2.1^{\circ}$ at $\mathrm{NPR}_{\mathrm{D}}=6$ and $\delta_{p}=2.0^{\circ}$ at $\mathrm{NPR}_{\mathrm{D}}=10$ with $3 \%$ secondary flow injection.

The system thrust ratio for the DTN nozzle (figure 20(b)) peaked at approximately NPR $=5, C_{f, g} s y s=0.95$ and then decreased with increasing NPR. Figure 21(b) presents the system thrust ratio for the nozzle with variable area ratio. At NPR $=6$, there was a significant penalty in $C_{f, g}$ sys of $6.2 \%$ compared to the DTN fixed geometry nozzle. As discussed previously for the data with no secondary injection (section III(A)), this is contrary to expectation. At $\mathrm{NPR}=10, C_{f, g}$ sys $=0.93$ for both the fixed area nozzle (figure 20(b)) and the variable area nozzle (figure 21(b)).

Increasing expansion ratio with increasing NPR improved discharge coefficient approximately $10 \%$ at NPR $\geq 6.0$ during thrust vectoring operation, compare figures $21(\mathrm{c})$ and 22(c). For the fixed geometry DTN shown in figure 20(c), discharge coefficient is generally flat for NPR $>2$, which is expected for a nozzle designed with $\mathrm{NPR}_{\mathrm{D}}=1.89$.

Similar to the non-vectoring case $\left(w_{s} /\left(w_{i, p}+w_{s}\right)=0\right)$ discussed in Section III(A) and III(B), the variable expansion ratio DTN did not provided the expected performance benefit during thrust vectoring operation versus the fixed design with $A_{e} / A_{t}=1.0$. System thrust ratio was better or the same throughout the flight envelope for the fixed area 
DTN. The variable geometry DTN provided a higher discharge coefficient throughout the entire flight envelop, however, it was not flat. The variation in discharge coefficient would have a negative impact on engine operability as discussed in section III(B). During thrust vectoring operation, the fixed geometry $\left(A_{e} / A_{t}=1.0\right)$ Dual Throat Nozzle provided a better compromise to thrust vector angle and internal nozzle performance than the Dual Throat Nozzle with variable expansion ratio capability over the range of NPR tested.

\section{Conclusions}

A dual throat nozzle concept has been extended from a two-dimensional rectangular nozzle studied previously (refs. 15-18) to an axisymmetric nozzle and the concept was tested experimentally in the Jet Exit Test Facility at the NASA Langley Research Center. Experimental data were recorded at nozzle pressure ratios up to 10 with secondary injection rates from 0 (no thrust vectoring) up to 10 percent of the primary nozzle flow rate. The axisymmetric dual throat nozzle was modified with a variable expansion ratio for applicability to supersonic aircraft. The geometric variables that were investigated were circumferential span of injection, cavity length, cavity convergence angle and expansion ratio for conditions corresponding to take-off and landing, mid climb and cruise. The data from the current experimental investigation of the axisymmetric dual throat nozzle indicated the following conclusions:

1. The dual throat nozzle concept generates the best thrust vectoring performance with a cavity in between two equal minimum areas $\left(A_{e} / A_{t}=1.0\right)$

2. The nozzle discharge coefficient decreased with increasing secondary injection rate. This is a concern of the DTN concept in that engine operability could be adversely affected.

3. During non-thrust vectoring operation (no injection), the variable expansion ratio nozzle provided only a slight improvement in primary thrust ratio versus the fixed geometry nozzle at the highest nozzle pressure ratios tested. The performance of the mid-climb nozzle with a design nozzle pressure ratio of 6 was substantially lower than the fixed geometry nozzle thrust ratio. However, primary discharge coefficient was substantially better for the variable geometry nozzle than the dual throat nozzle for nozzle pressure ratios up to 10 .

4. The 60 degree span of injection generally performed better than the 90 degree span of injection (using an equivalent injection area and number of holes spread out either 60 or 90 degrees around the circumference of the upstream minimum area. For injection rates less than 7 percent, thrust vector angle for the 60 degree span of injection was 1.5 to 2 degrees higher than the 90 degree span of injection. However, when corrected for model asymmetry the difference in thrust vector angle was minimal. These trends are in agreement with computational results documented reference 19.

5. In agreement with previous two-dimensional experimental dual throat nozzle results, decreasing cavity length improved thrust ratio and discharge coefficient, but decreased thrust vector angle and thrust vectoring efficiency.

6. Increasing cavity convergence angle from 20 to 30 degrees increased thrust vector angle by 1 degree over the range of injection rates tested and slightly improved thrust vectoring efficiency for injection rates less than 6 percent, but adversely effected system thrust ratio and discharge coefficient over the entire range of secondary injection rates tested.

7. During thrust vectoring operation, the fixed geometry $\left(A_{e} / A_{i}=1.0\right)$ Dual Throat Nozzle provided a better compromise to thrust vector angle and internal nozzle performance than the Dual Throat Nozzle with variable expansion ratio capability over the range of NPR tested.

\section{References}

${ }^{1}$ Anderson, C. J.; Giuliano, V. J.; and Wing, David J.: Investigation of Hybrid Fluidic / Mechanical Thrust Vectoring for Fixed-Exit Exhaust Nozzles. AIAA 97-3148, July 1997.

${ }^{2}$ Giuliano, V. J.; and Wing, David J.: Static Investigation of a Fixed-Aperture Exhaust Nozzle Employing Fluidic Injection for Multiaxis Thrust Vector Control. AIAA 97-3149, July 1997.

${ }^{3}$ Waithe, Kenrick A.: An Experimental and Computational Investigation of Multiple Injection Ports in a ConvergentDivergent Nozzle for Fluidic Thrust Vectoring. Master of Science Thesis, May 2001. 2000.

${ }^{4}$ Deere, K. A.: Computational Investigation of the Aerodynamic Effects on Fluidic Thrust Vectoring. AIAA 2000-3598, July

${ }^{5}$ Abeyounis, W. K.; and Bennett, B. D. Jr.: Static Internal Performance of an Overexpanded, Fixed-Geometry, Nonaxisymmetric Nozzle with Fluidic Pitch-Thrust-Vectoring Capability. NASA TP-3645, October 1997.

${ }^{6}$ Wing, David J.; and Giuliano, V. J.: Fluidic Thrust Vectoring of an Axisymmetric Exhaust Nozzle at Static Conditions. ASME FEDSM97-3228, June 1997.

${ }^{7}$ Chiarelli, C.; Johnsen, R. K.; Shieh, C. F.; Wing, D. J.: Fluidic Scale Model Multi-Plane Thrust Vector Control Test Results. AIAA 93-2433, June 1993. 
${ }^{8}$ Yagle, P. J., Miller, D. N., Ginn, K. B.; and Hamstra, J. W.: Demonstration of Fluidic Throat Skewing for Thrust Vectoring in Structurally Fixed Nozzles. 2000-GT-0013, May 8-11, 2000.

${ }^{9}$ Deere, K. A.: Summary of Fluidic Thrust Vectoring Research Conducted at NASA Langley Research Center. AIAA-2003-3800, June 2003.

${ }^{10}$ Hunter, C.A. and Deere, Karen A.: Computational Investigation of Fluidic Counterflow Thrust Vectoring. AIAA 99-2669, June 1999.

${ }^{11}$ Flamm, J. D.: Experimental Study of a Nozzle Using Fluidic Counterflow for Thrust Vectoring. AIAA 98-3255, July 1998.

${ }^{12}$ Miller, D. N.; Yagle, P. J.; and Hamstra, J. W.: Fluidic Throat Skewing for Thrust Vectoring in Fixed Geometry Nozzles. AIAA 99-0365, January 1999.

${ }^{13}$ Wing, David J.: Static Investigation of Two Fluidic Thrust-Vectoring Concepts on a Two-Dimensional ConvergentDivergent Nozzle. NASA TM-4574, December 1994.

${ }^{14}$ Deere, Karen A., and Wing, David J.: PAB3D Simulations of a Nozzle with Fluidic Injection for Yaw-Thrust-Vector Control. AIAA 98-3254, July 1998.

${ }^{15}$ Deere, K. A.; Berrier, B. L.; Flamm, J. D.; and Johnson, S. K.: Computational Study of Fluidic Thrust Vectoring Using Separation Control in a Nozzle. AIAA-2003-3803, June 2003.

${ }^{16}$ Deere, K. A.; Berrier, B. L.; Flamm, J. D.; and Johnson, S. K.: A Computational Study of a Dual Throat Fluidic Thrust Vectoring Nozzle Concept. AIAA-2005-3502, July 2005.

${ }^{17}$ Flamm, J. D.; Deere, K. A.; Berrier, B. L.; and Johnson, S. K.: An Experimental Study of a Dual Throat Fluidic Thrust Vectoring Nozzle Concept. AIAA-2005-3503, July 2005.

${ }^{18}$ Flamm, J. D.; Deere, K. A.; Mason, M. L.; Berrier, B. L.; and Johnson, S. K.: Design Enhancements of the TwoDimensional, Dual Throat Fluidic Thrust Vectoring Nozzle Concept. AIAA-2006-3701, June 2006.

${ }^{19}$ Deere, K. A.; Flamm, J. D.; Berrier, B. L.; and Johnson, S. K.: Computational Study of an Axisymmetric Dual Throat Fluidic Thrust Vectoring Nozzle Concept for Supersonic Aircraft Application. AIAA-2007-5085, July 2007.

${ }^{20}$ A User's Guide to the Langley 16-Foot Transonic Tunnel Complex, Revision 1. NASA TM-102750, 1990. (Supersedes NASA TM-83186)

${ }^{21}$ Berrier, Bobby L.; Leavitt, Laurence D.; and Bangert, Linda S.: Operating Characteristics of the Multiple Critical Venturi System and Secondary Calibration Nozzles Used for Weight-Flow Measurements in the Langley 16-Foot Transonic Tunnel. NASA TM-86405, 1985.

${ }^{22}$ Abdol-Hamid, K. S.: The Application of 3D Marching Scheme for the Prediction of Supersonic Free Jets. AIAA 89-2897. July 1989.

${ }^{23}$ Abdol-Hamid, K. S.: Application of a Multiblock/ Multizone Code (PAB3D) for the Three-Dimensional Navier-Stokes Equations. AIAA-91-2155, June 1991.

${ }^{24}$ Carlson, J. R.: A Nozzle Internal Performance Prediction Method. NASA TP 3221, October 1992.

${ }^{25}$ Carlson, J. R.: Computational Prediction of Isolated Performance of an Axisymmetric Nozzle at Mach Number 0.90. NASA TM 4506, February 1994.

${ }^{26}$ Pao, S. P., Carlson, J. R., and Abdol-Hamid, K. S.: Computational Investigation of Circular-to-Rectangular Transition Ducts. Journal of Propulsion and Power, Vol. 10, No. 1, p 95-100, Jan.-Feb. 1994.

${ }^{27}$ Abdol-Hamid, K. S.; Lakshmanan, B.; and Carlson, J. R.: Application of Navier-Stokes Code PAB3D With k- $\varepsilon$ Turbulence Model to Attached and Separated Flows. NASA TP-3480, January 1995.

${ }^{28}$ Abdol-Hamid, K. S., Carlson, J. R., and Pao, S. P.: Calculation of Turbulent Flows Using Mesh Sequencing and Conservative Patch Algorithm. AIAA 95-2336, July 1995.

${ }^{29}$ Pao, S. P.; and Abdol-Hamid, K. S.: Numerical Simulation of Jet Aerodynamics Using the Three-Dimensional NavierStokes Code PAB3D. NASA TP 3596, September 1996.

${ }^{30}$ Abdol-Hamid, K. S.; Lakshmanan, B.; and Carlson, J. R.: Application of Navier-Stokes Code PAB3D With k- $\varepsilon$ Turbulence Model to Attached and Separated Flows. NASA TP-3480, January 1995.

${ }^{31}$ Carlson, J. R.: Applications of Algebraic Reynolds Stress Turbulence Models Part 1: Incompressible Flat Plate. Journal of Propulsion and Power, Vol. 13, No. 5, p 610-619, Sept.-Oct. 1997.

${ }^{32}$ Abdol-Hamid, K., Pao, S., Massey, S., and Elmiligui, A.: Temperature Corrected Turbulence Model for High Temperature Jet Flow. ASME Journal of Fluids Engineering, Vol. 126, No. 5, September 2004.

${ }^{33}$ Abdol-Hamid, K. S. and Girimaji, S. S.: A Two-Stage Procedure Toward the Efficient Implementation of PANS and Other Hybrid Turbulence Models. NASA/TM-2004-213260, August 2004.

${ }^{34}$ Massey, S. J.; and Abdol-Hamid, K. S.: Enhancement and Validation of PAB3D for Unsteady Aerodynamics. AIAA 2003-1235, January 2003.

${ }^{35}$ Elmiligui, A., Abdol-Hamid, K., and Hunter, C.: Numerical Investigation of Flow in an Over-expanded Nozzle with Porous Surfaces. AIAA 2005-4159, July 2005. 


\begin{tabular}{|c|c|c|c|c|c|c|c|}
\hline Configuration & $d_{2}$ (in.) & $\theta_{2}(\mathrm{deg})$ & $A_{e}\left(\mathrm{in}^{2}\right)$ & $A_{e} / A_{t}$ & $l$ (in.) & $\mathrm{NPR}_{\mathrm{D}}$ & $\begin{array}{c}\text { Injection } \\
\text { Span } \\
(\mathrm{deg})\end{array}$ \\
\hline $13-60$ & 2.42 & 30 & 4.6 & 1.0 & 5.26 & 1.89 & 60 \\
\hline $13-90$ & 2.42 & 30 & 4.6 & 1.0 & 5.26 & 1.89 & 90 \\
\hline $15-60$ & 2.94 & 20 & 6.79 & 1.48 & 5.26 & 6 & 60 \\
\hline $14-60$ & 3.36 & 11 & 8.87 & 1.93 & 5.26 & 10 & 60 \\
\hline $25-60$ & 2.42 & 30 & 4.6 & 1.0 & 4.21 & 1.89 & 60 \\
\hline $28-60$ & 2.42 & 20 & 4.6 & 1.0 & 4.21 & 1.89 & 60 \\
\hline$d_{1}=2.42$ in., $\phi=150$ deg., $A_{t}=4.6$ in. ${ }^{2}, \theta_{1}=-10$ deg. for all configurations \\
\hline
\end{tabular}

Table 1. Experimental Nozzle Geometric Design Variables

\begin{tabular}{|c|c|c|c|}
\hline Component & $\begin{array}{c}\text { Balance } \\
\text { Maximum }\end{array}$ & $\begin{array}{c}\text { Maximum } \\
\text { Error }\end{array}$ & $\begin{array}{c}\text { Max error as } \\
\text { percentage of } \\
\text { Balance } \\
\text { Maximum }\end{array}$ \\
\hline Normal & $800 \mathrm{lbf}$ & $0.56 \mathrm{lbf}$ & 0.07 \\
Axial & $1200 \mathrm{lbf}$ & $2.38 \mathrm{lbf}$ & 0.20 \\
Pitch & $12000 \mathrm{in}-\mathrm{lbf}$ & $17.64 \mathrm{in}-\mathrm{lbf}$ & 0.15 \\
Roll & $1000 \mathrm{in}-\mathrm{lbf}$ & $1.63 \mathrm{in}-\mathrm{lbf}$ & 0.16 \\
Yaw & $12000 \mathrm{in}-\mathrm{lbf}$ & $26.07 \mathrm{in}-\mathrm{lbf}$ & 0.22 \\
Side & $800 \mathrm{lbf}$ & $0.47 \mathrm{lbf}$ & 0.06 \\
\hline
\end{tabular}

Table 2. Balance accuracy.

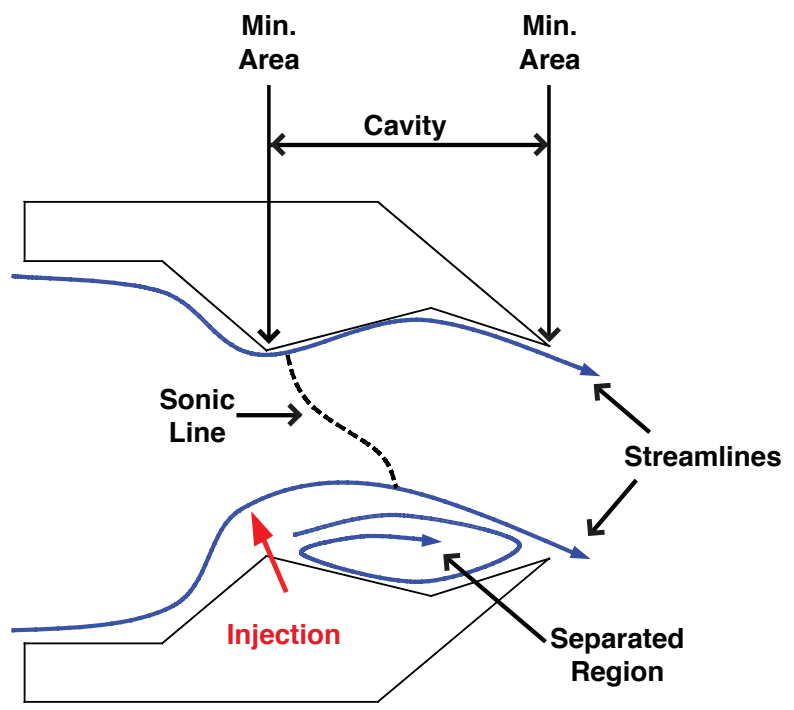

Figure 1. Sketch of the dual throat fluidic thrust vectoring nozzle. 


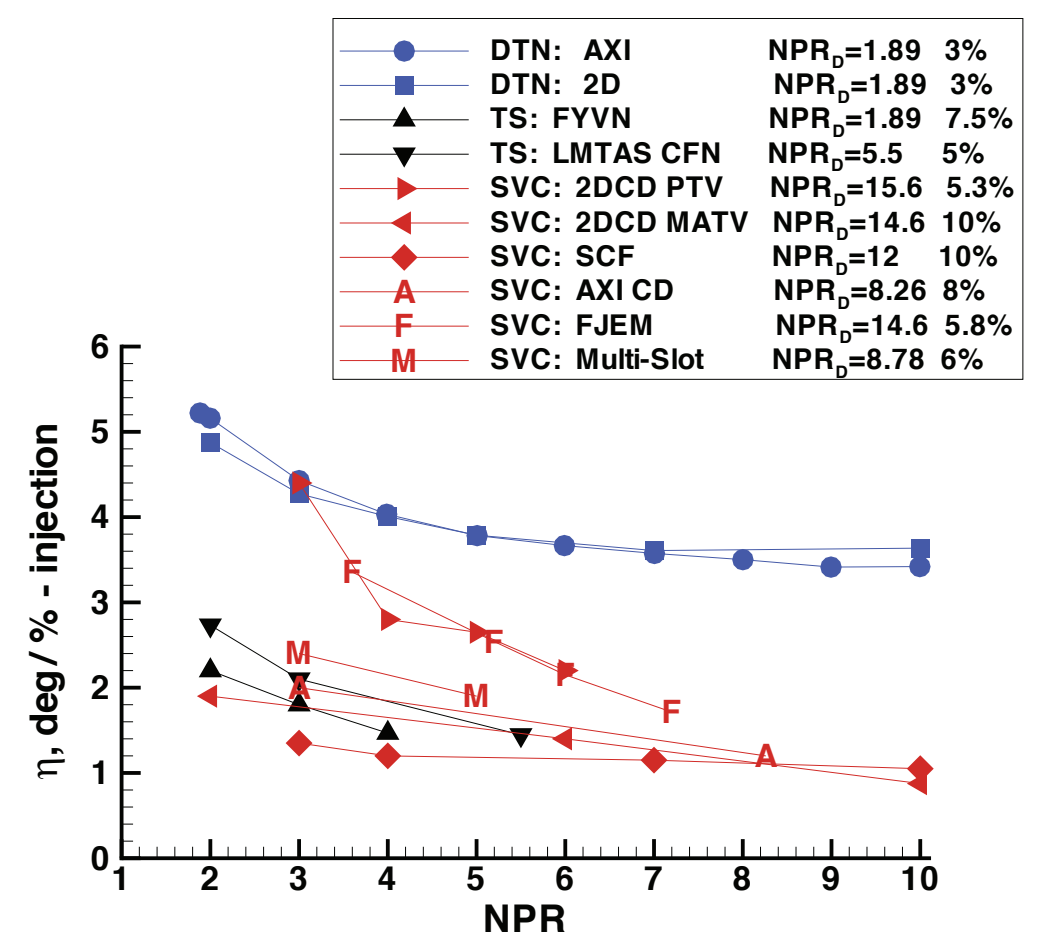

(a) Thrust Vectoring Efficiency

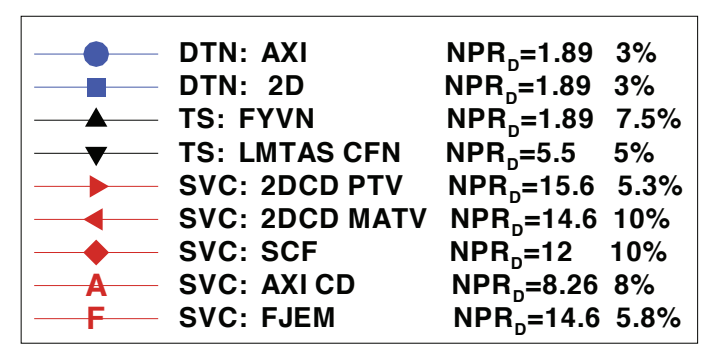

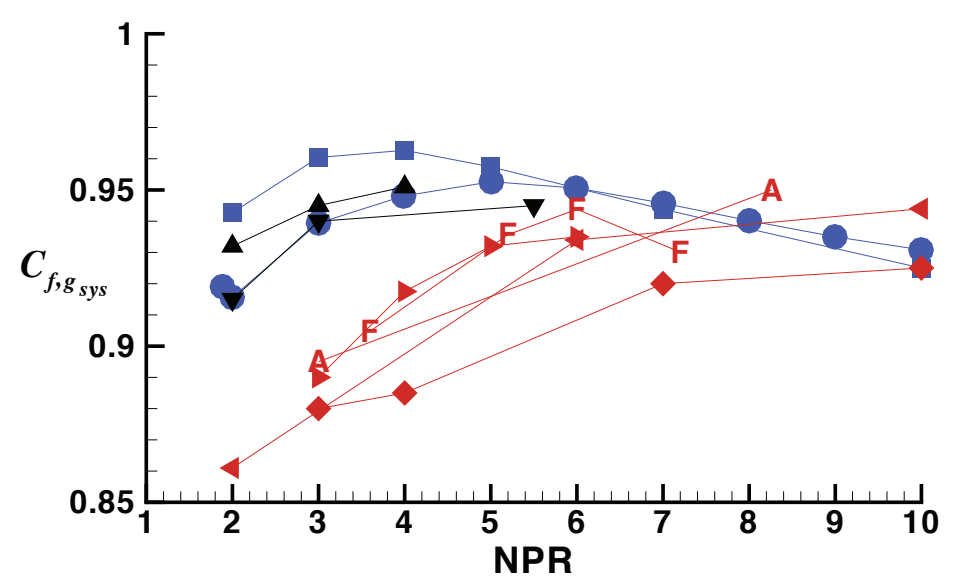

(b) Thrust Efficiency

Figure 2. Comparison of experimental dual throat nozzle (DTN) thrust vectoring efficiency and thrust efficiency to other Throat Shifting (TS) and Shock Vector Control (SVC) methods (refs. 1-9 and 18). 


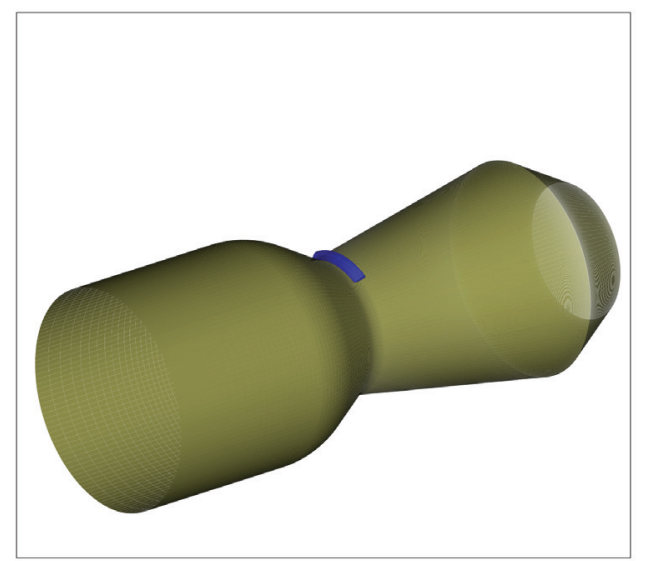

(a) Pitch injection plenum shown in blue.

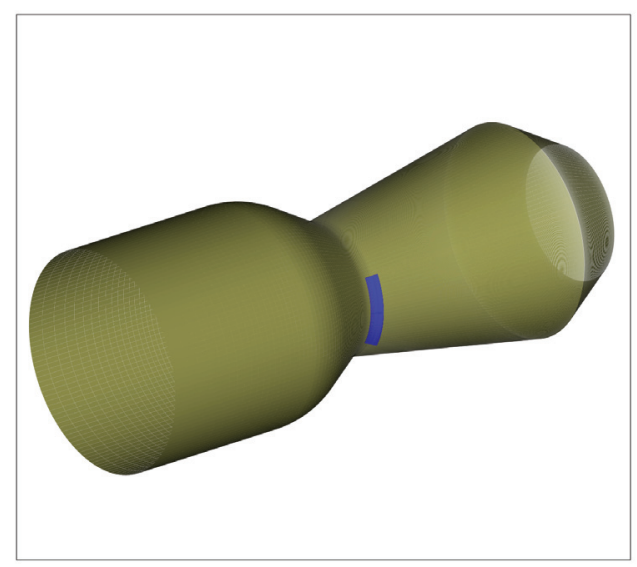

(b) Yaw injection plenum shown in blue.

Figure 3. Axisymmetric DTN with injection plenum located at the upstream minimum area.

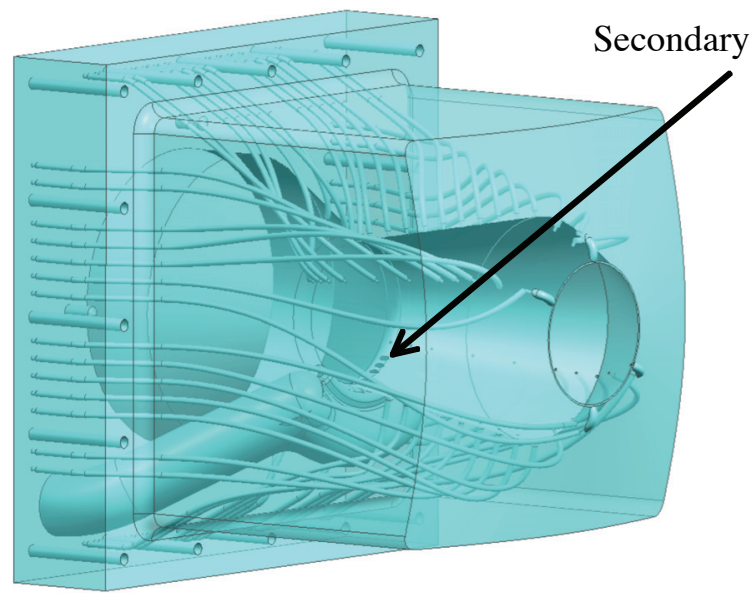

Figure 4. CAD image of an axisymmetric DTN model. 


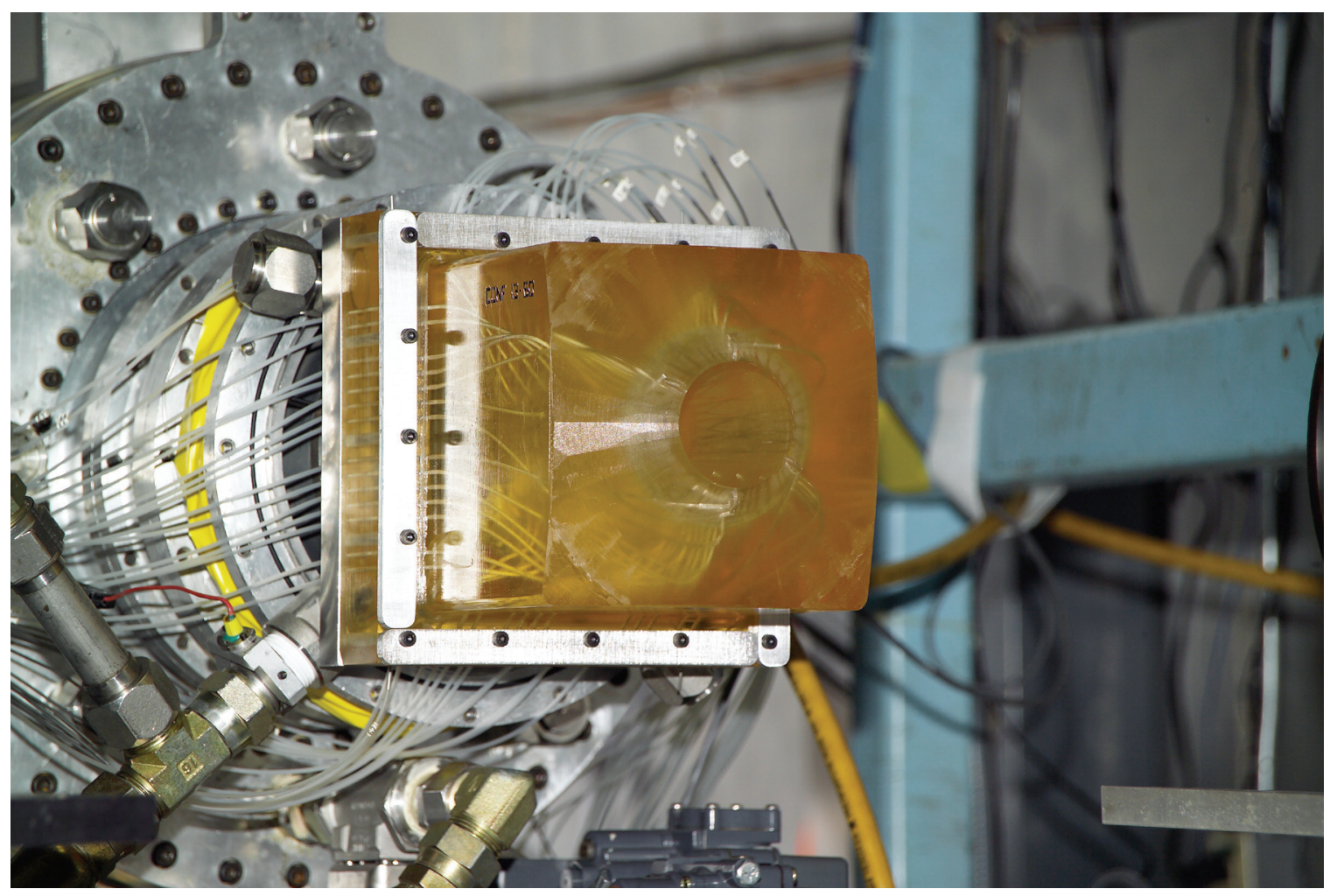

Figure 5. Photograph of a stereo lithography model of an axisymmetric DTN mounted to the propulsion simulation system in the NASA LaRC Jet Exit Test Facility.

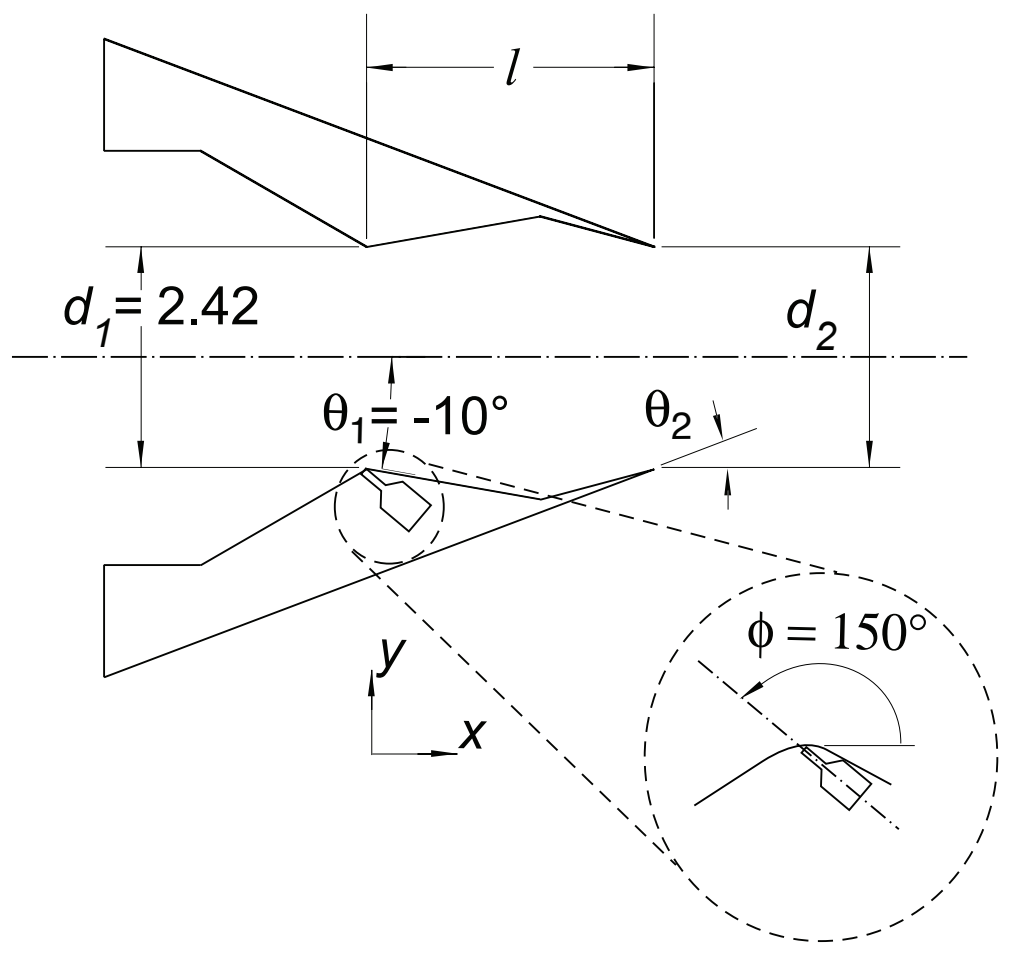

Figure 6. The design variables for the DTN. 


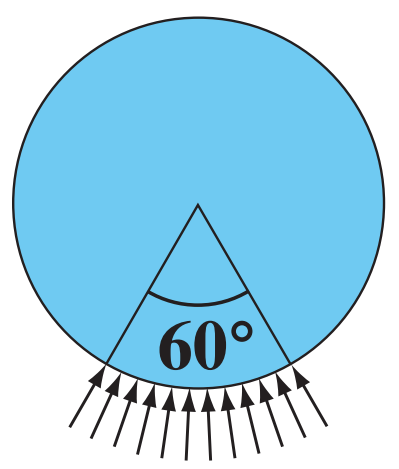

(a) $60^{\circ}$ span of injection

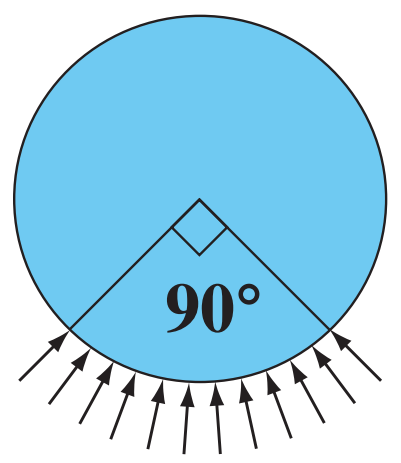

(b) $90^{\circ}$ span of injection

Figure 7. Circumferential spans of injection.

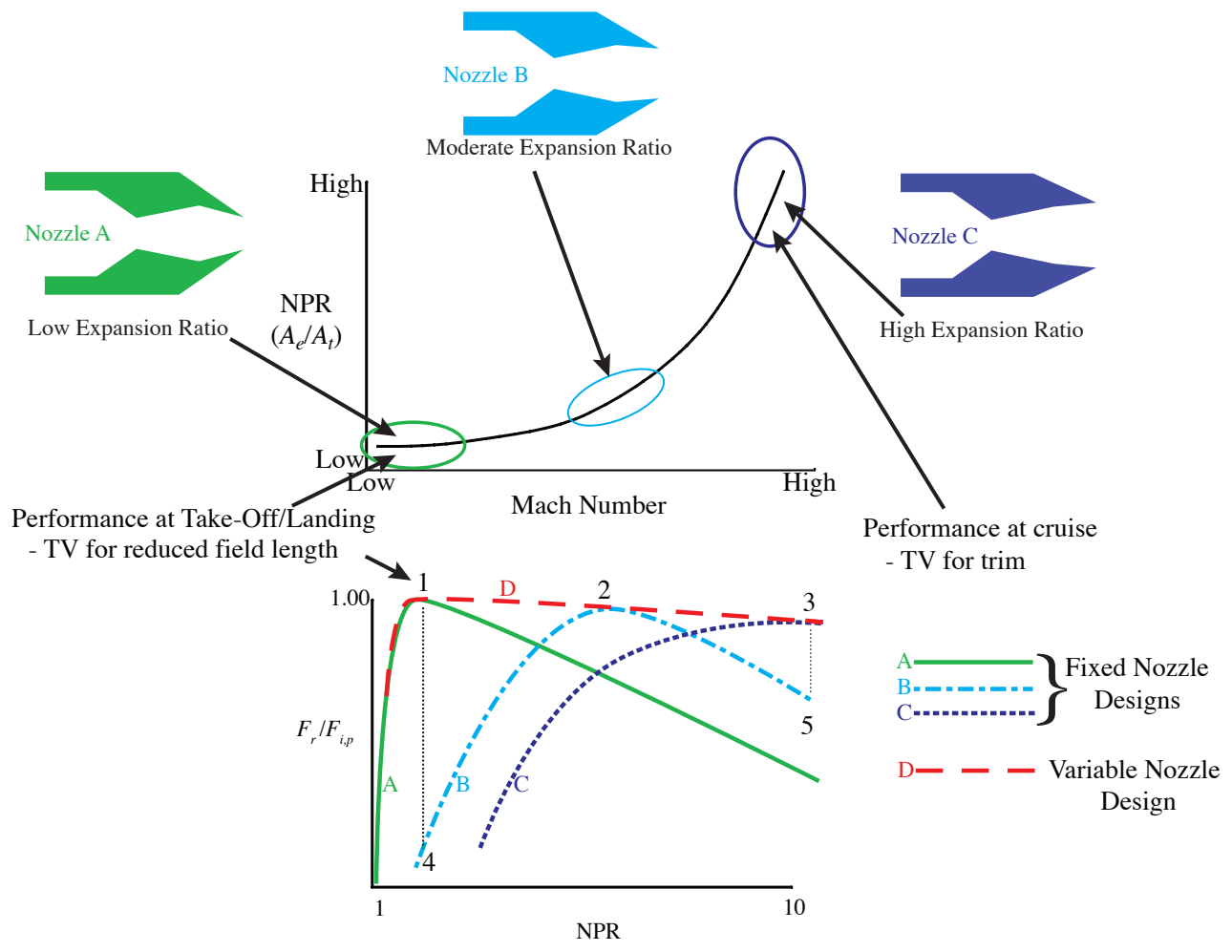

Figure 8. Variable area nozzle operating curve. 

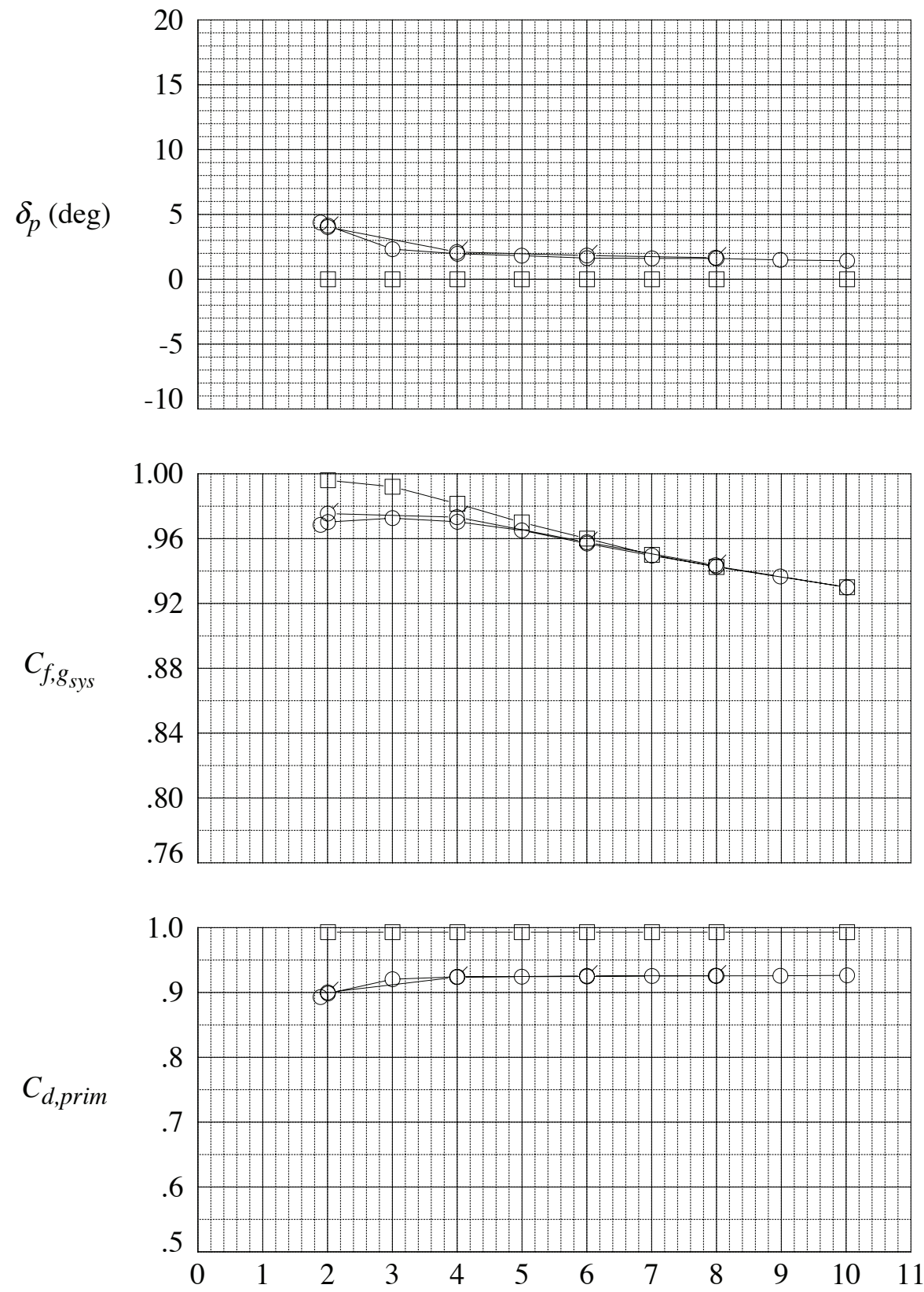

$N P R$

Figure 9. Effect of nozzle pressure ratio (NPR) on internal nozzle performance with no injection for the baseline model (13-60) and a typical convergent nozzle. Cavity Length $=5.26$ in., $\theta_{1}=-10^{\circ}, \theta_{2}=30^{\circ}, A_{e} / A_{t}=1.0$. Note: flagged symbols indicate data taken in descending order of NPR. 

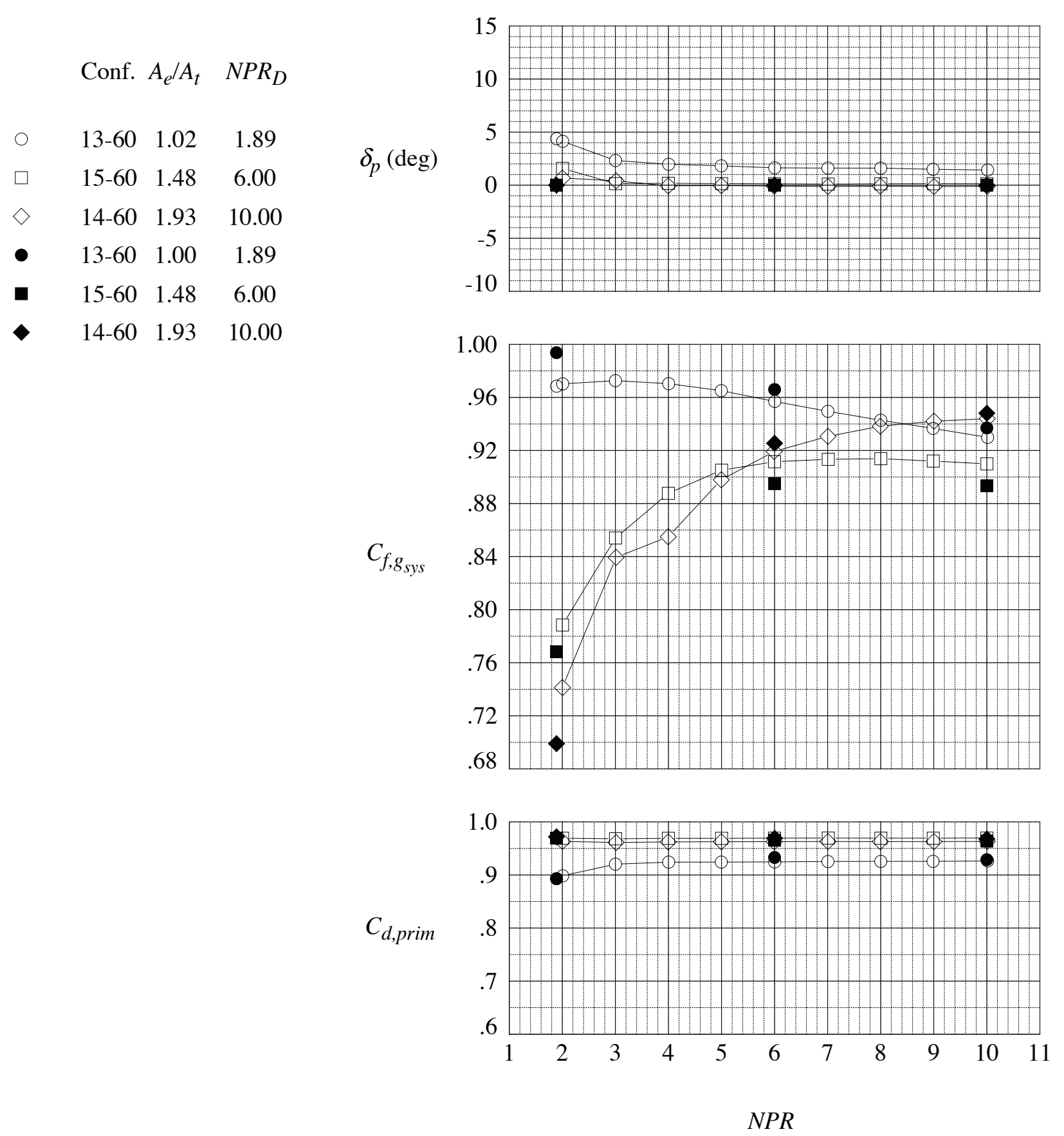

Figure 10. Effect of nozzle pressure ratio (NPR) on internal nozzle performance with no injection for the family of nozzles with Cavity Length $=5.26$ in, $\theta_{1}=-10^{\circ}$, and varying area ratio. Open symbols experimental data. Solid symbols computational data. 


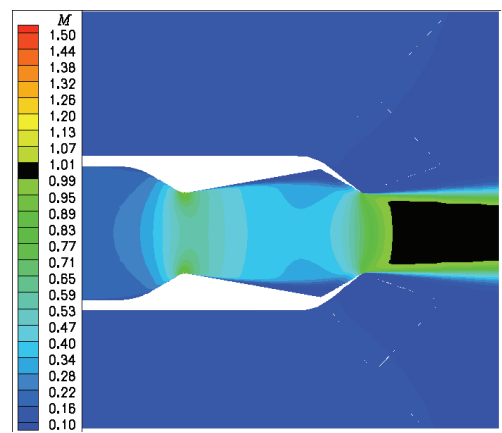

(a) Configuration $13\left(A_{e} / A_{t}=1.0\right)$

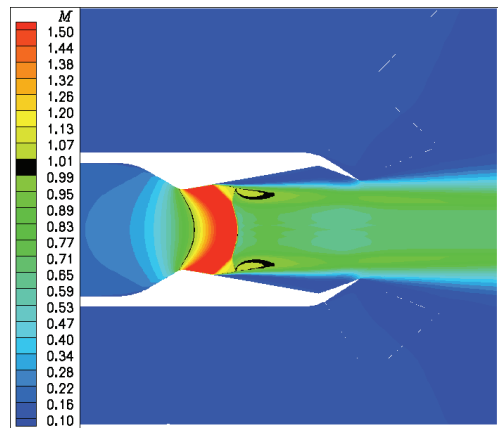

(b) Configuration $15\left(A_{e} / A_{t}=1.47\right)$

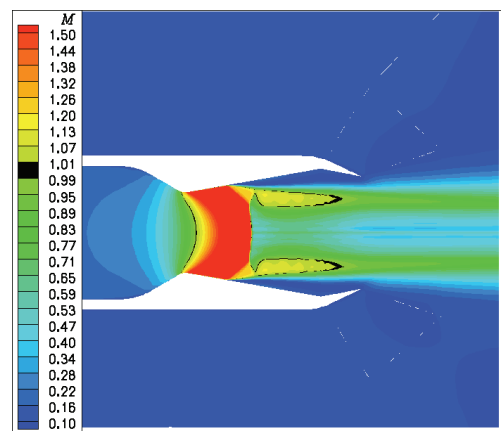

(c) Configuration $14\left(A_{e} / A_{t}=1.93\right)$

Figure 11. Computational Mach contours, NPR=1.89, no injection.

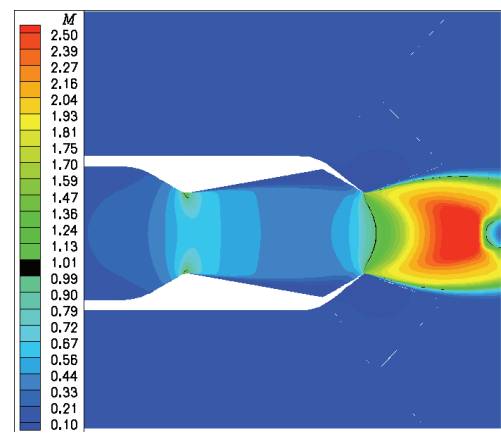

(a) Configuration $13\left(A_{e} / A_{t}=1.0\right)$

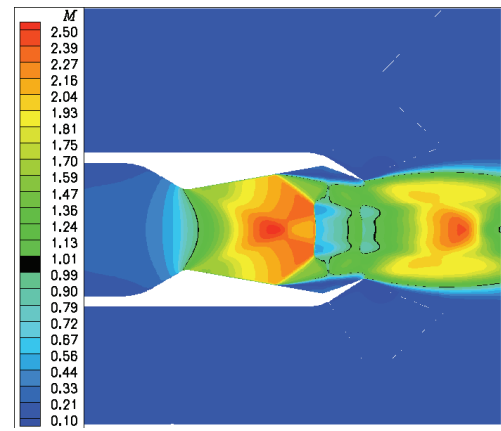

(b) Configuration $15\left(A_{e} / A_{t}=1.47\right)$

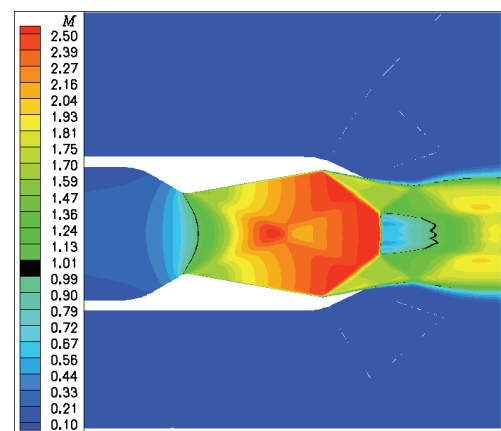

(c) Configuration $14\left(A_{e} / A_{t}=1.93\right)$

Figure 12. Computational Mach contours, NPR=6, no injection.

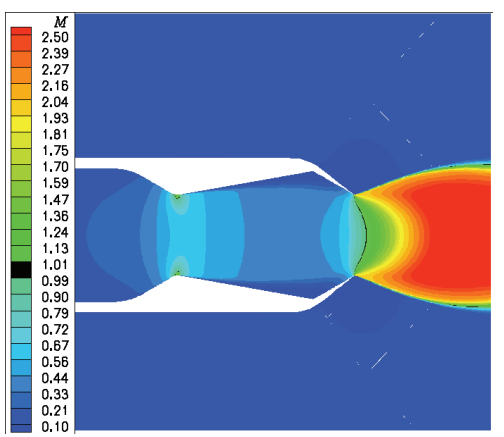

(a) Configuration $13\left(A_{e} / A_{t}=1.0\right)$

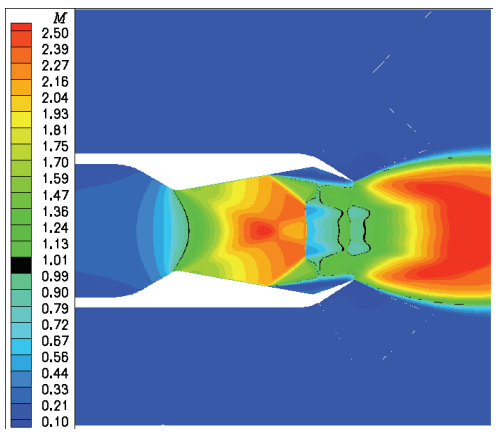

(b) Configuration $15\left(A_{e} / A_{t}=1.47\right)$

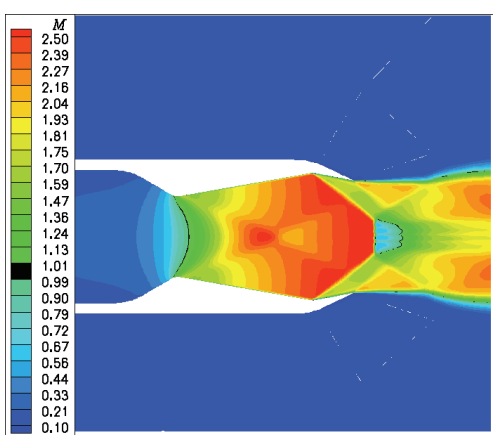

(c) Configuration $14\left(A_{e} / A_{t}=1.93\right)$

Figure 13. Computational Mach contours, NPR=10, no injection. 


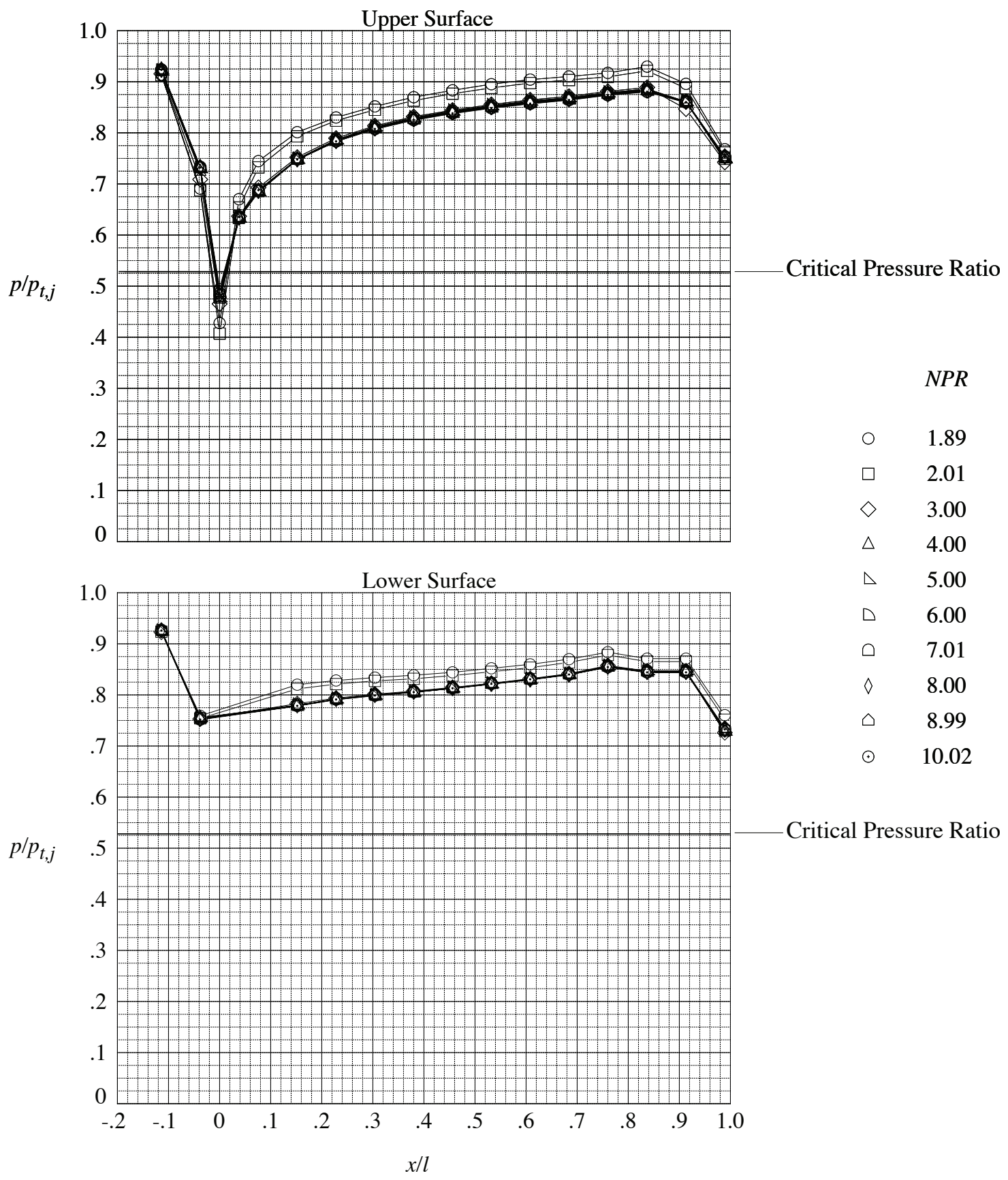

(a) Configuration 13-60

Figure 14. Experimental surface pressure distributions along nozzle centerline, no injection. Note: There is no pressure measurement on the lower nozzle surface at $x / l=0$ due to the presence of the secondary injection holes. Therefore, the curve faring is erroneous in this location. 


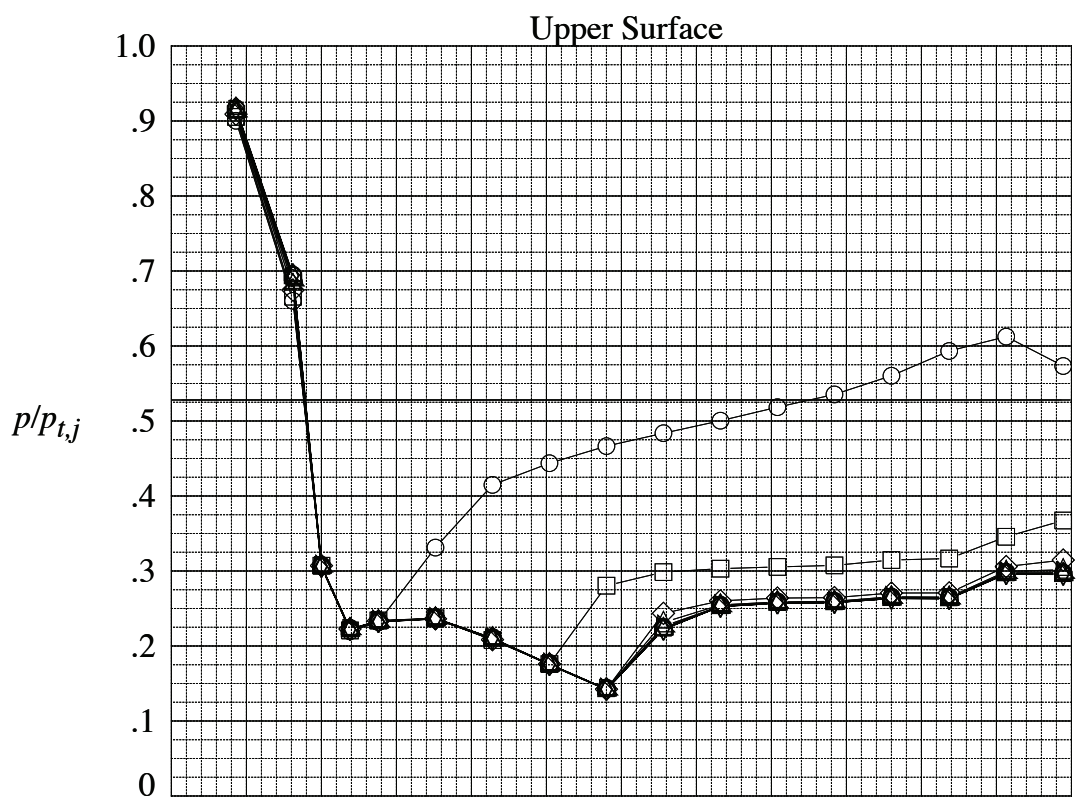

Critical Pressure Ratio

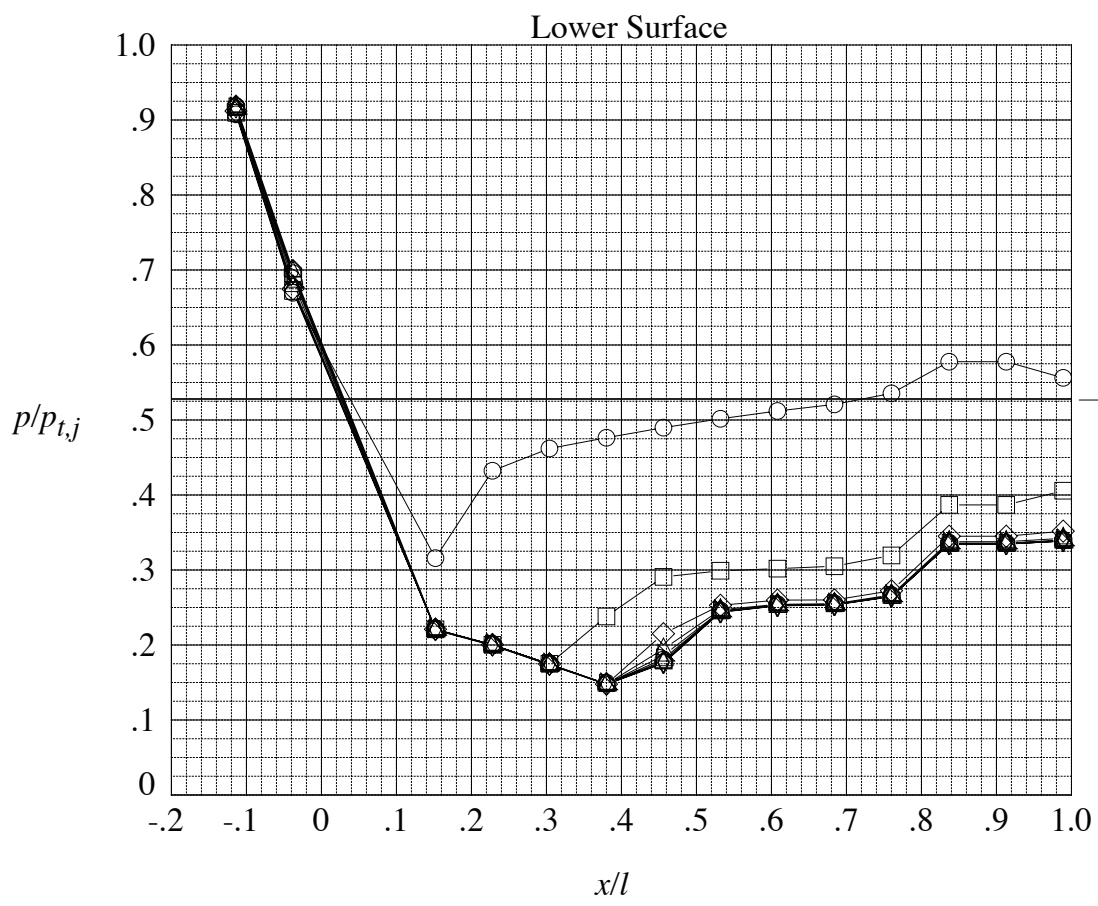

$\begin{array}{cc} & N P R \\ \triangleright & 2.00 \\ \square & 3.00 \\ \diamond & 4.00 \\ \triangle & 5.00 \\ \triangle & 6.00 \\ \triangleright & 7.01 \\ \triangle & 8.00 \\ \diamond & 8.99 \\ \triangle & 10.00\end{array}$

(b) Configuration 15-60

Figure 14. Continued. 


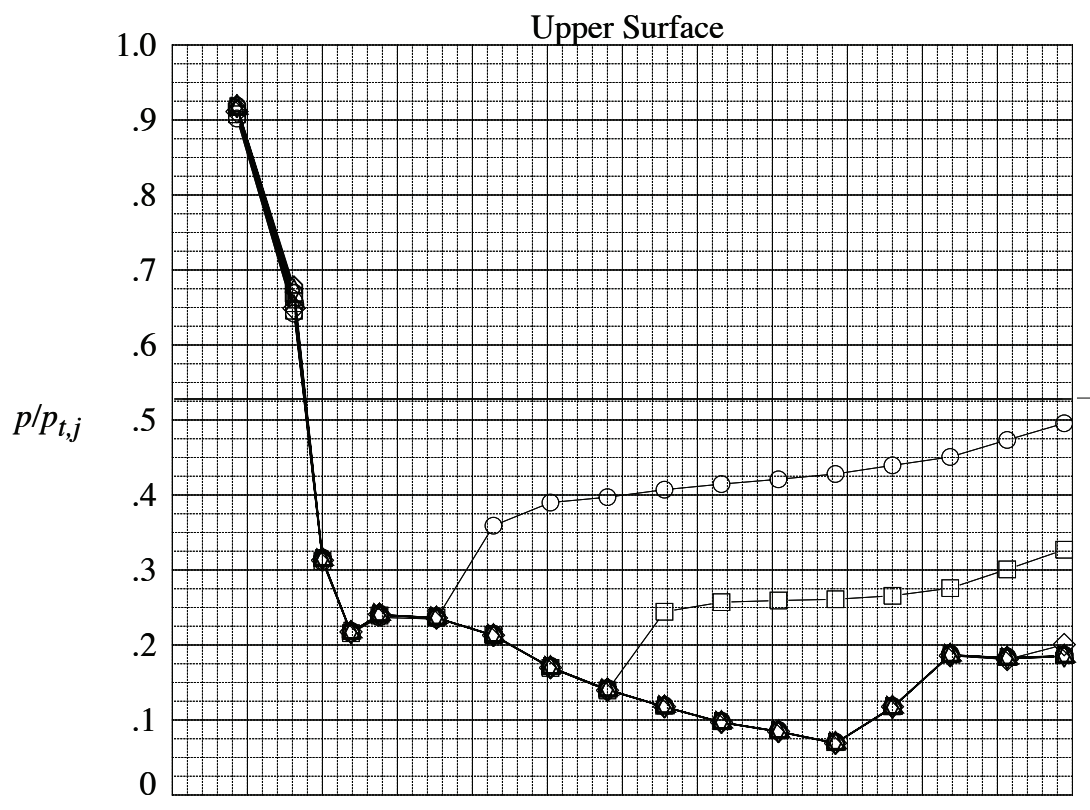

Critical Pressure Ratio

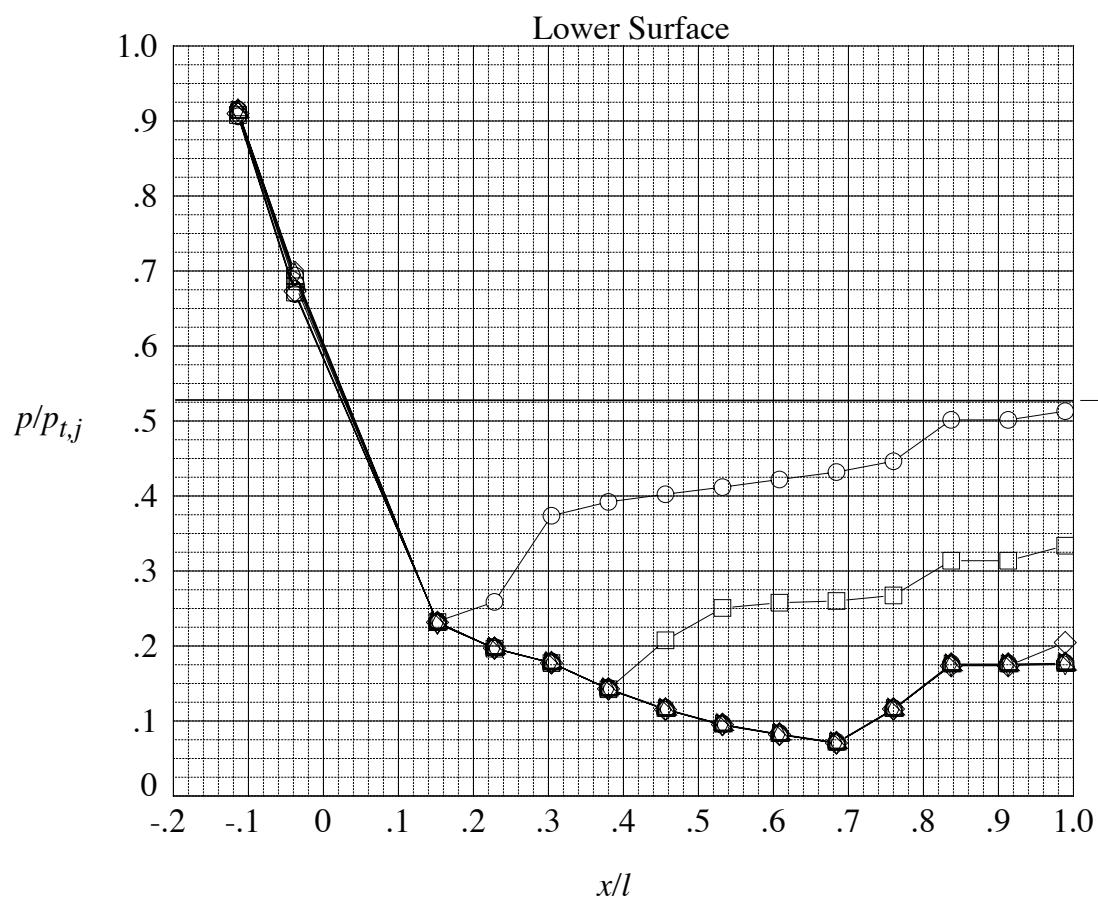

Critical Pressure Ratio

(c) Configuration 14-60

Figure 14. Concluded. 

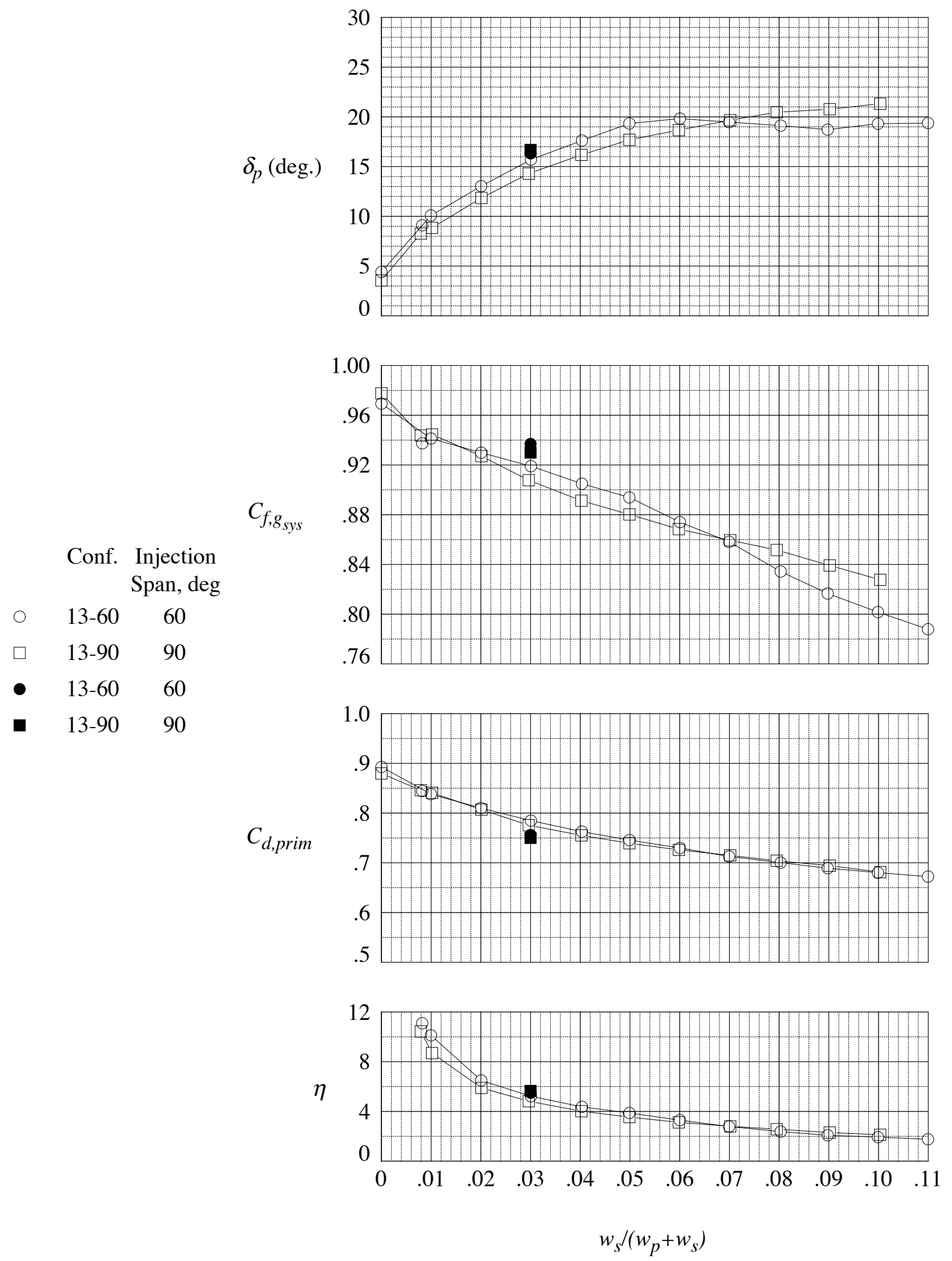

Figure 15. Effect of secondary injection span on internal nozzle performance. NPR $=1.89$, Cavity Length $=5.26$ in, $\theta_{1}=-10^{\circ}, \theta_{2}=30^{\circ}$. Open symbols experimental data. Solid symbols computational data. 


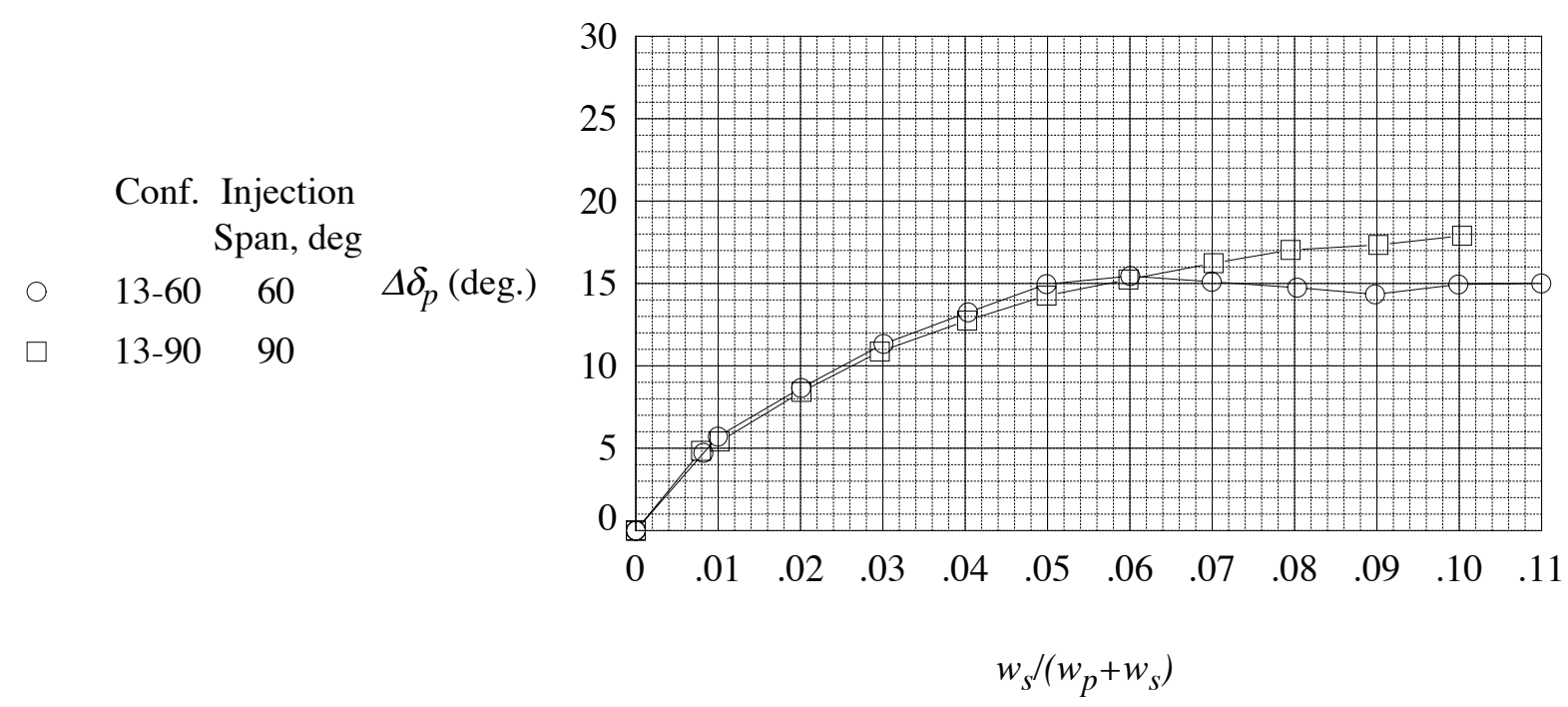

Figure 16. Effect of secondary injection span on nozzle thrust vectoring performance. Data corrected for offset from zero with no secondary injection. NPR $=1.89$, Cavity Length $=5.26$ in, $\theta_{1}=-10^{\circ}, \theta_{2}=30^{\circ}$. 

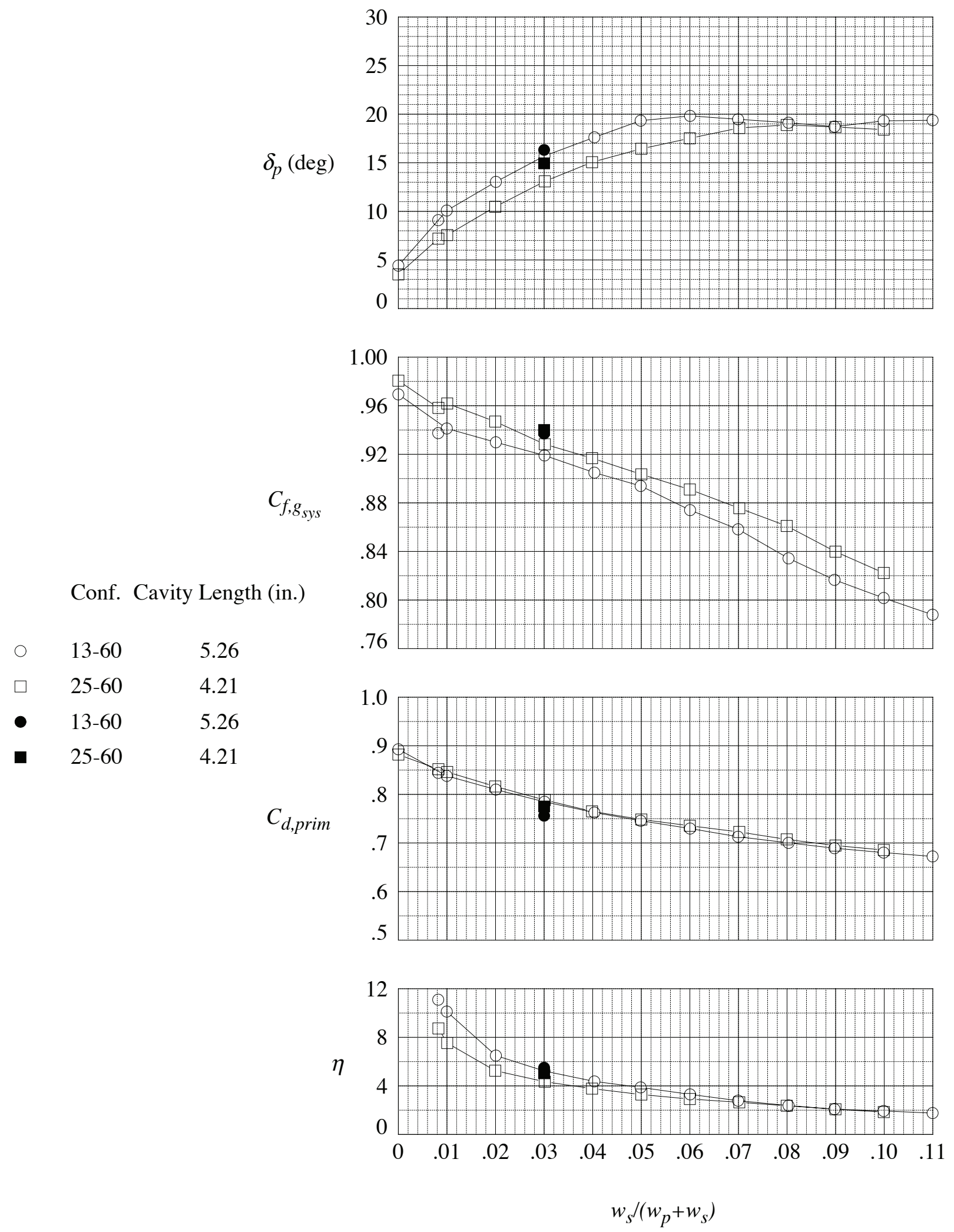

Figure 17. Effect of cavity length on internal nozzle performance. NPR $=1.89, \theta_{1}=-10^{\circ}, \theta_{2}=30^{\circ}$. Open symbols experimental data. Solid symbols computational data. 


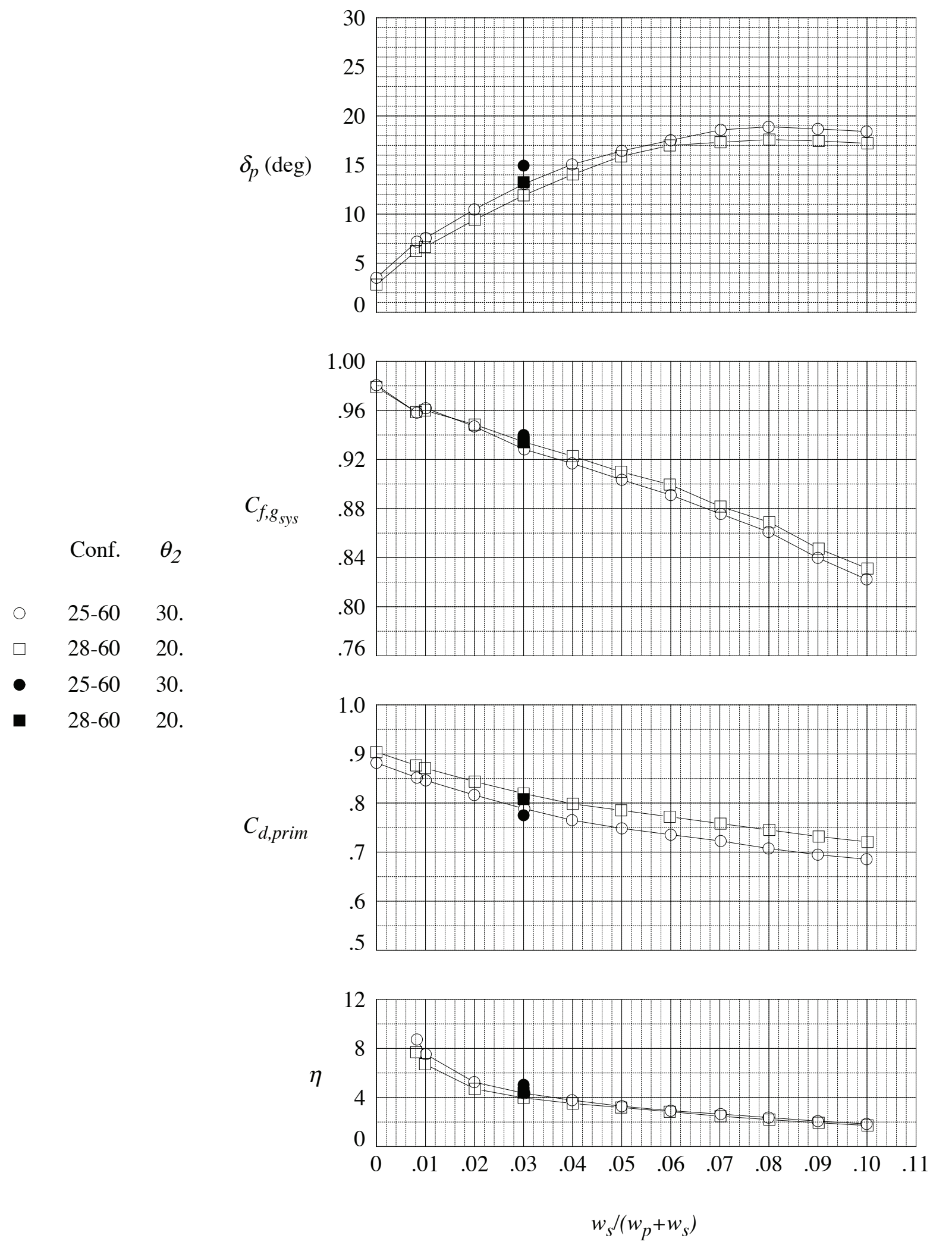

Figure 18. Effect of cavity convergence angle on internal nozzle performance. NPR $=1.89, l=4.21$ in., $\theta_{1}=-10^{\circ}$. Open symbols experimental data. Solid symbols computational data. 

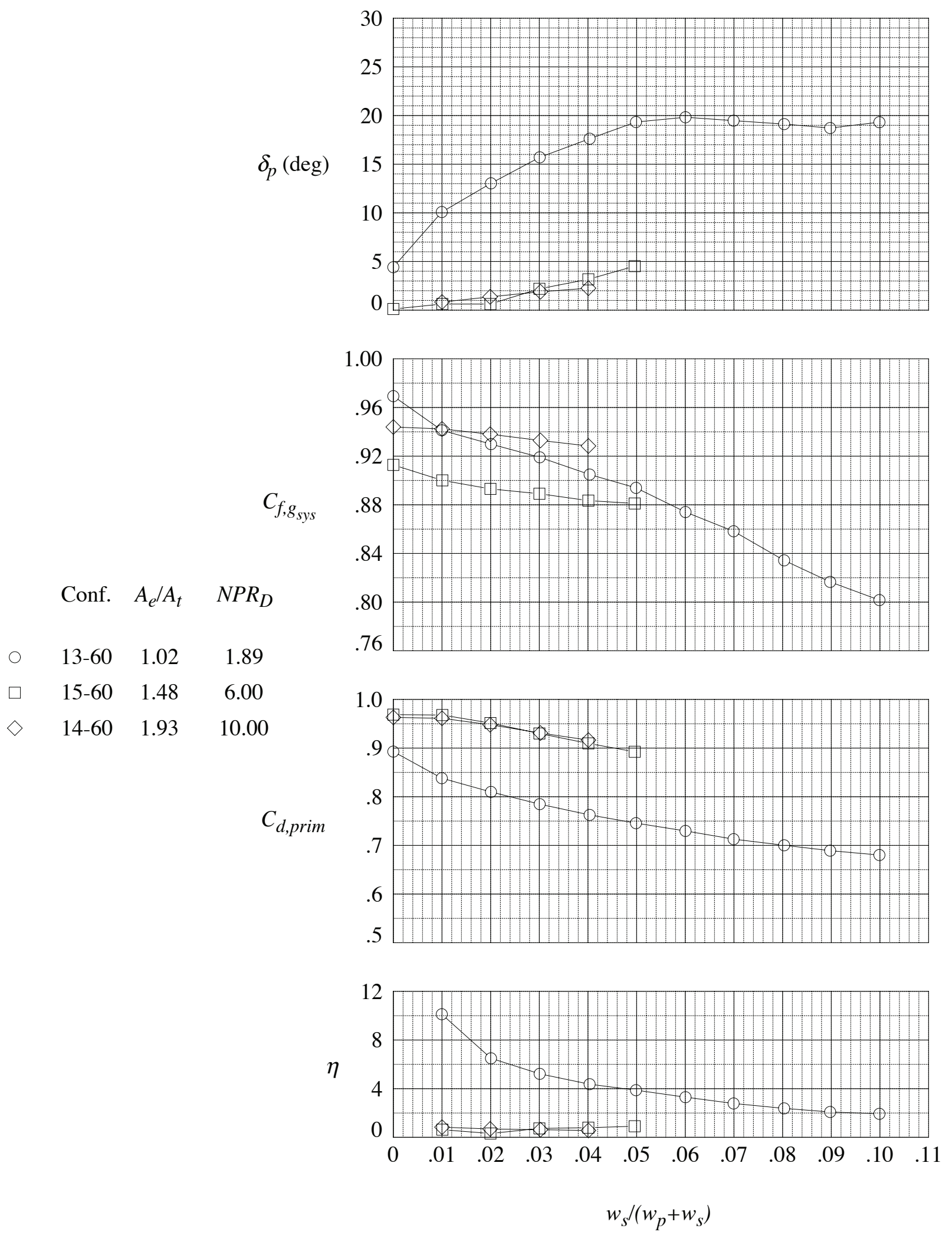

Figure 19. Nozzle internal performance for the family of nozzles with Cavity Length $=5.26$ in., $\theta_{1}=-10^{\circ}$, and varying area ratio with secondary injection. $\mathrm{NPR}=\mathrm{NPR}$ for each configuration. 
\begin{tabular}{l}
-O-CFD \\
$-\square-$ Experiment \\
\hline
\end{tabular}

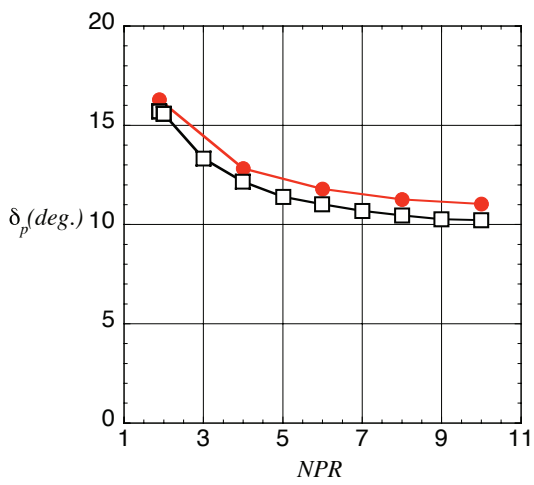

(a) Thrust vector angle
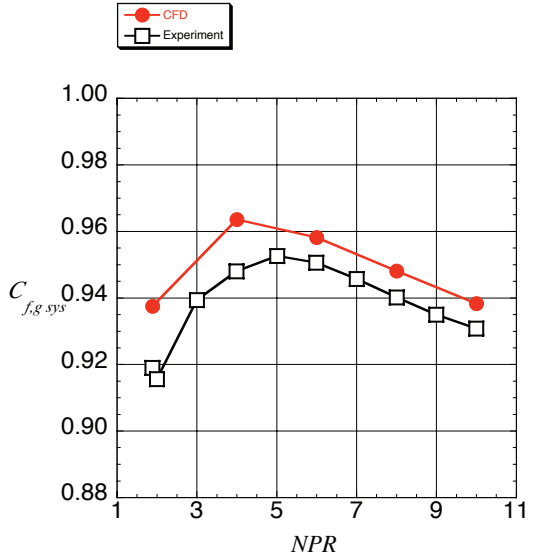

(b) System thrust ratio

$$
\begin{aligned}
& -0 \text {-CFD } \\
& -\square \text {-Experiment } \\
& \hline
\end{aligned}
$$

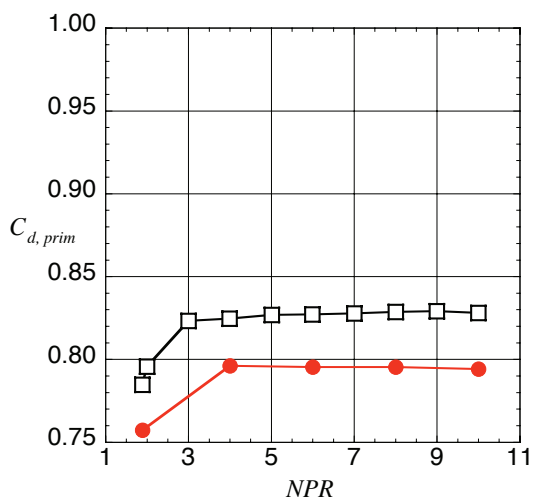

(c) Discharge coefficient

Figure 20. Nozzle internal performance for a fixed geometry, configuration $13-60, \mathrm{~A}_{\mathrm{e}} / \mathrm{A}_{\mathrm{t}}=1.0$, operating over a range of NPR with $3 \%$ fluidic injection. Static Free-stream. Open symbols experimental data. Solid symbols computational data.

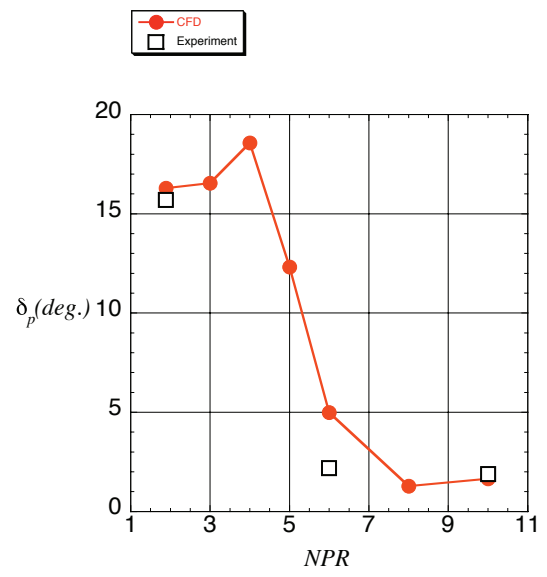

(a) Thrust vector angle
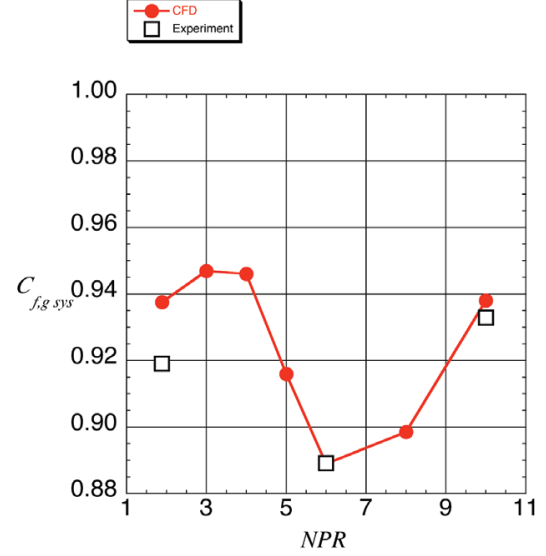

(b) System thrust ratio
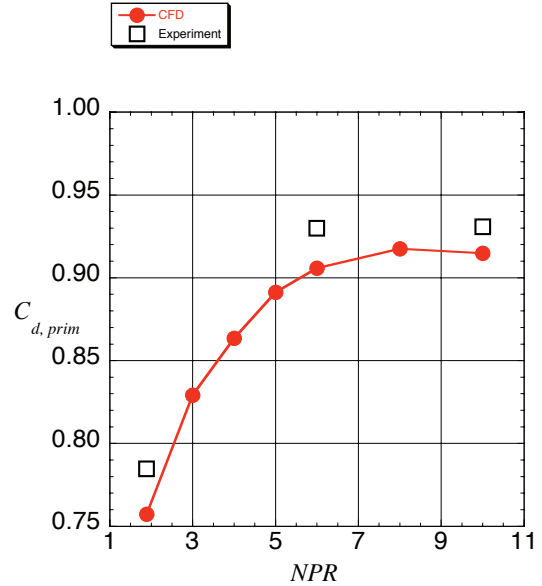

(c) Discharge coefficient

Figure 21. Nozzle internal performance with varying expansion ratio (configurations 13-60, 15-60, 14-60) operating over a range of NPR with $3 \%$ fluidic injection. Static Free-stream. Open symbols experimental data. Solid symbols computational data. 